Christian-Albrechts-Universität zu Kiel

Bachelor's thesis

in "Physics of the Earth System (B.Sc.)"

\title{
Impact of ocean resolution on storms in the North Atlantic region
}

Johanna Knauf

Student ID: 1131291

6th November 2020

Supervised by:

Prof. Dr. Joakim Kjellsson,

Dr. Annika Reintges 


\section{Abstract}

In this study the impact of ocean resolution in the FOCI2-OpenIFS climate model on synoptic variability in the North Atlantic region is studied. FOCI2-OpenIFS consists of the atmospheric model OpenIFS and the oceanic model NEMO which has a resolution of $1 / 2^{\circ}$ in the standard model run (FOCI-standard). In order to resolve eddies, the oceanic resolution in the North Atlantic can be increased to $1 / 10^{\circ}$ by embedding an ocean nest for another model run (FOCI-nest). The impact of this increased ocean resolution is studied by comparing FOCI-standard to FOCI-nest and evaluating the model biases of both runs by comparing them to observations and reanalysis data.

An analysis of the climatology shows that the sea-surface temperature (SST), mean sea-level pressure (MSLP), zonal wind $(u)$ and precipitation biases to reanalysis data and observations are smaller in FOCI-nest than in FOCI-standard. The MSLP and $u$ biases strongly depend on the season. Compared to FOCI-standard, $u$ indicates a northward shift of the polar jet stream in FOCI-nest.

The frequency and magnitude of the North Atlantic Oscillation was evaluated for FOCI-standard, FOCI-nest and reanalysis data. The corresponding PC1 to EOF1 of MSLP shows an irregular multiyear variability in FOCI-standard but a regular 3-4 years variability in FOCI-nest. This regular variability in FOCI-nest might not have the physical meaning of the North Atlantic Oscillation.

MSLP variance and heat flux $\left(\overline{v^{\prime} T^{\prime}}\right)$ were calculated using an Eulerian approach with 2-8 days bandpass-filtering. MSLP variance biases to reanalysis are reduced in FOCI-nest compared to FOCI-standard. Both MSLP variance and heat flux indicate a northward shift of storm activity in FOCI-nest compared to FOCI-standard.

Individual midlatitude cyclones were traced using a Lagrangian storm tracking algorithm. It was found that the spatial distribution of storm track, genesis, and lysis density, storm growth and decay, mean intensity and mean lifetime is similar for FOCI-standard and FOCI-nest. The largest differences between the two model runs are locally higher storm track and genesis densities at around $60^{\circ} \mathrm{N}$, lower magnitudes of zonal mean storm growth and decay and a higher lifetime of storms north of $32^{\circ} \mathrm{N}$ in FOCI-nest compared to FOCI-standard. 
The results of the Eulerian and Lagrangian approach differ in the location of the storm activity maximum. MSLP variance and heat flux indicate a storm activity maximum over the southeast coast of North America at around $50^{\circ} \mathrm{N}$ whereas the spatial distribution of track density shows a maximum over the Irminger Sea.

\section{Zusammenfassung}

In dieser Bachelorarbeit wird der Einfluss der Ozeanauflösung im Klimamodell FOCI2-OpenIFS auf die synoptische Variabilität in der Nordatlantikregion untersucht. FOCI2-OpenIFS besteht aus dem Atmosphärenmodell OpenIFS und dem Ozeanmodell NEMO, welches eine Auflösung von 1/2 ${ }^{\circ}$ im Standardmodelldurchlauf (FOCI-standard) hat. Um Eddies aufzulösen, kann die Ozeanauflösung im Nordatlantik auf $1 / 10^{\circ}$ erhöht werden, indem ein sogenanntes Ozean-Nest für einen weiteren Modelldurchlauf (FOCI-nest) eingebettet wird. Der Einfluss dieser erhöhten Ozeanauflösung wird untersucht, indem FOCI-standard mit FOCI-nest verglichen wird und die Abweichungen der Modelle zu Beobachtungs- und Reanalysedaten ausgewertet werden.

Eine Analyse der Klimatologie zeigt, dass die Abweichungen der Meeresoberflächentemperatur (SST), des Luftdrucks auf Meereshöhe (MSLP), des zonalen Windes $(u)$ und des Niederschlages von FOCI-nest zu den Reanalyse- und den Beobachtungsdaten kleiner sind als die von FOCI-standard. Die Abweichungen von MSLP und $u$ hängen stark von der Jahreszeit ab. Aus der Analyse von $u$ ergibt sich eine nordwärtige Verschiebung des Polarjets in FOCI-nest im Vergleich zu FOCI-standard.

Die Frequenz und Magnitude der Nordatlantischen Oszillation wurde für FOCIstandard, FOCI-nest und die Reanalysedaten ausgewertet. Die zugehörige PC1 der EOF1 des MSLP zeigt eine unregelmäßige mehrjährige Variabilität in FOCIstandard wohingegen FOCI-nest eine regelmäßige 3-4-jährige Variabilität aufweist. Diese regelmäßige Variabilität in FOCI-nest hat möglicherweise nicht die physikalische Bedeutung der Nordatlantischen Oszillation.

2-8-tägige Bandpassfilterung wurde im Eulerschen Ansatz genutzt, um die MSLPVarianz und den Wärmefluss $\left(\overline{v^{\prime} T^{\prime}}\right)$ zu berechnen. Die Abweichungen der MSLP Varianz zwischen der Reanalyse und den Modelldaten sind kleiner in FOCI-nest als in FOCI-standard. Im Vergleich von FOCI-nest zu FOCI-standard, weisen sowohl 
die MSLP Varianz als auch der Wärmefluss auf eine nordwärtige Verschiebung der Sturmaktivität in FOCI-nest hin.

Stürme in den mittleren Breiten wurden einzeln mit einem Lagrangeschen Sturmverfolgungsalgorithmus aufgezeichnet. Es wurde festgestellt, dass die räumliche Verteilung der Sturmdichte, Sturmentstehungs- und Sturmauflösungsdichte, der Sturmintensivierung und -abschwächung, der mittleren Intensität und Lebensdauer ähnlich in FOCI-standard und FOCI-nest ist. Die größten Unterschiede bestehen in einer lokal erhöhten Sturmdichte und Sturmentstehungsdichte um $60^{\circ} \mathrm{N}$, eines insgesamt schwächeren zonalen Mittels der Intensitätszunahme und -abnahme und einer höheren Lebensdauer von Stürmen nördlich von $32^{\circ} \mathrm{N}$ in FOCI-nest im Vergleich zu FOCIstandard.

Die Ergebnisse des Eulerschen und des Lagrangeschen Ansatzes unterscheiden sich in der Verortung des Sturmaktivitätsmaximums. Während die MSLP-Varianz und der Wärmefluss auf ein Sturmaktivitätsmaximum an der Südostküste von Nordamerika bei etwa $50^{\circ} \mathrm{N}$ hindeuten, zeigt die räumliche Verteilung der Lagrangeschen Sturmdichte ein Maximum über der Irmingersee. 


\section{Contents}

1 Introduction $\quad 1$

2 Data and Methodology 4

2.1 Data Description . . . . . . . . . . . . . . . . . 4

2.2 Methodology . . . . . . . . . . . . . . . . . 6

$\begin{array}{llr}3 & \text { Results } & 8\end{array}$

3.1 Model Climatology and Bias . . . . . . . . . . . . . . . . 9

3.2 Variability . . . . . . . . . . . . . . . . . . . . . 14

3.3 Heat Flux and North Atlantic Oscillation . . . . . . . . . . . . . 16

3.4 Lagrangian Storm Tracking . . . . . . . . . . . . . . . . . . 20

4 Summary and Discussion $\quad 26$

5 Conclusion $\quad 30$

6 Acknowledgements 31

7 References $\quad 32$ 


\section{Introduction}

Reliable modelling of storms in the North Atlantic region is important for the understanding and prediction of extreme weather events in eastern North America and western Europe. However, the changes in storm activity in a changing climate are not yet fully understood. Anthropogenic climate change is expected to cause a decrease in the meridional temperature gradient due to Arctic Amplification which influences the midlatitude circulation (Francis and Vavrus, 2012; Barnes and Polvani, 2015) and reduces the baroclinicity which is important for the genesis of cyclones (Wang et al., 2017). Thus, the storm activity could decrease. But lower tropospheric specific humidity is expected to increase (Held and Soden, 2006), which might increase storm activity because increased humidity strengthens eddy baroclinicity (Booth et al., 2013; Emanuel et al., 1987). In order to study the predominant effect of changes in climatology on storm activity, the requirements of climate models for storm modelling should be identified. In this thesis the impact of ocean resolution on storm modelling by FOCI2-OpenIFS in the North Atlantic region is studied. For this purpose two versions of the model with (FOCI-nest) and without (FOCI-standard) an enhancement of the ocean resolution from $1 / 2^{\circ}$ to $1 / 10^{\circ}$ in the North Atlantic are compared.

Brayshaw et al. $(2009,2011)$ discussed the ingredients of the North Atlantic storm track by composing a set of semirealistic experiments to identify the crucial effects for the formation of the extratropical North Atlantic storm track in comparison to zonal storm tracks on an aquaplanet. They found that the North Atlantic storm track is determined by land-sea contrast, orography and sea-surface temperature (SST) anomalies:

The land-sea contrast favours baroclinicity because of the higher heating capacity of the oceans than of land and the heat transport by currents in the ocean. This leads to a confluence of cold continental air and warm air close to the surface of the ocean and therefore strong baroclinicity. Over extratropical landmasses storm formation is prevented by a high surface drag and small moisture availability but over the oceans with small surface drag and high moisture availability the baroclinicity leads to storm formation (Brayshaw et al., 2009).

The orography influences the flow of the westerlies which can either be deflected vertically over the mountains or meridionally around them. This depends on the ratio of the needed vertical potential temperature difference to the meridional potential temperature difference. Thus, the deflected flow over the northern parts 
of the Rocky Mountains generates an anticyclone while the deflected flow around the southern parts of the Rocky Mountains generates a cyclone. This leads to a southwest-northeast tilt of the North Atlantic storm track (Brayshaw et al., 2009). The SST anomalies produced by the Gulf Stream and the North Atlantic Drift lead to stronger winds in the western North Atlantic near $40^{\circ} \mathrm{N}$ and in higher latitudes and weaker winds in the eastern North Atlantic at around $40-50^{\circ} \mathrm{N}$. This combination strengthens the southwest-northeast tilt induced by the Rocky Mountains (Brayshaw et al., 2011). The cold SST anomaly north of the Gulf Stream reduces the land-sea contrast and therefore reduces the storm track activity on the northern east coast of North America (Brayshaw et al., 2009).

This thesis focuses on the influence of SST on storms in the North Atlantic region by increasing the ocean resolution to enhance its representation. Models of the North Atlantic climate system often show a cold SST bias in the central North Atlantic and a warm bias close to the North American coast at around $45^{\circ} \mathrm{N}$ (e.g. 22 CMIP5 models in Wang et al., 2014). These biases are a result of the Gulf Stream separating too far north from the coast of North America and its rather eastward than northeastward direction through the Atlantic in coarse ocean models (Keeley et al., 2012) or of a missing Gulf Stream representation. Greatbatch et al. (2010) highlighted the importance of eddy momentum fluxes for the Gulf Stream Extension region. Therefore, a Gulf Stream Extension that is too weak, too short or missing in non-eddying (horizontal resolution $(\Delta x) \sim 100 \mathrm{~km}$ ) or eddy-permitting $(\Delta x \sim 25 \mathrm{~km})$ ocean models has a strong influence on the northwestern Atlantic. A realistic representation of the Gulf Stream in an eddy-resolving $(\Delta x \sim 10 \mathrm{~km})$ ocean model could therefore reduce the SST biases and enhance the storm tracks in the North Atlantic (Hoskins and Valdes, 1989; Brayshaw et al., 2011). Hallberg (2013) showed that a grid of $1 / 8^{\circ}$ to $1 / 12^{\circ}$ is necessary to resolve eddies at around $50^{\circ} \mathrm{N}$.

The approach to use high resolution models to enhance the representation of largescale circulation and small-scale processes is systematically addressed by the High Resolution Model Intercomparison Project (HighResMIP) of the Coupled Model Intercomparison Project 6 (CMIP6). It aims to identify which climate model biases are caused by insufficient horizontal resolution. For this purpose coupled models with an eddy-permitting ocean resolution of $1 / 4^{\circ}$ are used. It was found that increased horizontal resolution (atmospheric $80 \mathrm{~km}$ to $40 \mathrm{~km}$, oceanic $1^{\circ}$ to $1 / 4^{\circ}$ ) in EC-Earth3P(-HR) does not result in an overall reduction of biases (Haarsma et al., 2020). FOCI bridges the gap between these eddy-permitting climate models and 
global high resolution weather models by using a North Atlantic eddy-resolving ocean nest to study the atmospheric response to an eddy-resolving ocean (Matthes et al., 2020).

Roberts et al. (2019) found that increased horizontal resolution reduces the cold bias in the North Atlantic, and that increasing ocean resolution (from $25 \mathrm{~km}$ to $8 \mathrm{~km}$ ) was more effective for this reduction than increasing atmospheric resolution $(100 \mathrm{~km}$ to $50 \mathrm{~km}$ ). Willison et al. (2015) showed that North Atlantic storm track sensitivity to global warming increases with model resolution. Therefore non-eddy-resolving climate models might underestimate an increase in storm activity in a changing climate.

Storms can be identified using Eulerian and Lagrangian approaches. The Eulerian approaches analyse atmospheric changes linked to storm activity at fixed points in space. These include mean sea-level pressure (MSLP) variance and heat flux $\left(\overline{v^{\prime} T^{\prime}}\right)$. Blackmon et al. (1977) introduced synoptic-time scale bandpass-filtering of 12-hourly sea-level pressure as a method to locate storm activity. Raphael (1997) highlighted the correlation of heat flux to midlatitude storm tracks. The Lagrangian approach follows features that are linked to a storm. Neu et al. (2013) compared different methods of storm tracking. The results vary depending on the underlying definition and identification method for extratropical cyclones. The algorithms are mainly based on tracking of either MSLP minima, MSLP gradients or vorticity. Hoskins and Hodges (2019a,b) used bandpass-filtered vorticity and meridional wind in combination with a Lagrangian feature tracking approach to identify storm activity in ERA-interim data. They described the general pattern of storm track activity over the course of a year. In the lower troposphere North Atlantic storm track densities have a maximum in winter and a minimum in summer. The storm tracks are generally at higher latitudes in summer and autumn than in winter and spring and have highest intensities in winter and lowest intensities in summer.

In this thesis, both Eulerian and Lagrangian methods are used to identify storm tracks in climate model simulations using either an eddy-permitting $\left(1 / 2^{\circ}\right)$ or eddyresolving $\left(1 / 10^{\circ}\right)$ ocean model to identify the change in biases in storm modelling when the ocean resolution is increased. 


\section{Data and Methodology}

This chapter gives an overview of the models used in this thesis and describes how storm activity was studied using data from these models.

\subsection{Data Description}

FOCI2-OpenIFS (Flexible Ocean and Climate Infrastructure 2 - Open Integrated Forecast System) is an Atmosphere-Ocean General Circulation Model (AOGCM) developed by GEOMAR using OASIS3-MCT4 to couple the atmospheric model OpenIFS 40r1 and the oceanic model NEMO v3.6 (Matthes et al., 2020; Kjellsson et al., 2020).

OASIS3-MCT4 (Ocean Atmosphere Sea Ice Soil - Model Coupling Toolkit) is a coupling library in Fortran which interpolates and exchanges the coupling fields of the oceanic and the atmospheric model every 3 hours in parallel (Craig et al., 2017).

The atmospheric model OpenIFS 40r1 is based on IFS (Integrated Forecast System) from the ECMWF (European Centre for Medium-Range Weather Forecasts). It has a horizontal resolution of $1.125^{\circ}$ and 91 vertical levels $(E C M W F, 2014)$. In comparison to FOCI1 (Matthes et al., 2020), which uses the atmospheric model ECHAM with a resolution of $1.8^{\circ}$, the increased atmospheric resolution of $1.125^{\circ}$ in FOCI2OpenIFS could improve orographic drag which influences storm tracks (Kjellsson et al., 2020). Orographic drag is modelled in OpenIFS 40r1 with the turbulent orographic form drag scheme (TOFD). TOFD uses the standard deviation of orography data on a $1 \mathrm{~km}$ resolution to parameterize orography and its effect integrated over all contributing wave numbers taking the wind forcing into account (IFS Documentation Part IV: Physical Processes by ECMWF, 2014). It should be noted that the resolution of $1.125^{\circ}$ might still lead to an underestimation of air-sea fluxes, limiting the atmospheric response to increased ocean resolution because the air-sea flux is calculated in the coarse atmospheric model and not in the higher resolution ocean model (Kjellsson et al., 2020).

The ocean model NEMO v3.6 (Nucleus for European Modelling in the Ocean, Madec, 2016) models ocean dynamics and thermodynamics and includes LIM2 (Louvain-laNeuve sea-ice model, Fichefet and Maqueda, 1997) as a three-layer sea-ice and snow model with viscous-plastic rheology. NEMO v3.6 uses a general ocean resolution of $1 / 2^{\circ}$ and 46 vertical levels (Matthes et al., 2020) on a tripolar grid with two 
northern poles over Canada and Russia to avoid too small grid cells at high latitudes (Madec and Imbard, 1996). Eddies are parameterized at this resolution (Gent and McWilliams, 1990). To realize an eddy-resolving ocean in the North Atlantic while limiting the computational cost, AGRIF (Debreu et al., 2008) was used to embed a nest of increased ocean resolution of $1 / 10^{\circ}$ in the North Atlantic $\left(30-85^{\circ} \mathrm{N}\right.$ : FOCI_VIKING10). In combination with this spatial nesting, the baroclinic time step was decreased from 1800s to 600s, the eddy-parameterization was removed and the bi-Laplacian viscosity and isoneutral diffusion were adapted (Matthes et al., 2020).

For this thesis, the data from the last 42 years of a 92 year test run with and without the North Atlantic ocean nest FOCI_VIKING10 was analysed. The data from the model run without ocean nesting is referred to as FOCI-standard. The data from the model run with the North Atlantic ocean nest is referred to as FOCI-nest. The term FOCI2 summarizes common features of both FOCI-standard and FOCI-nest. The data is available in 12 hour time steps (for bandpass analysis) and in monthly means.

In order to identify biases, model data is compared to ERA-Interim data. ERAInterim is reanalysis data by ECMWF from 1979 to date. The atmospheric model is IFS $31 \mathrm{r} 2$ and is based on a reduced Gaussian grid with $79 \mathrm{~km}$ spacing for surface fields. It has a T255 spherical-harmonic representation for basic dynamical fields and 60 vertical levels (Dee et al., 2011). It is to be noted that OpenIFS and ERA-Interim both use the ECMWF IFS model which may cause alignments of model errors in regions of low observation densities. Nevertheless, the combination of OpenIFS and ERA-Interim was chosen for this thesis because the North Atlantic region has a high density of observations constraining the reanalysis model which should minimize the impact of model errors in the ERA-Interim data.

Since precipitation is not an assimilated variable in ERA-Interim, and both OpenIFS and ERA-Interim use the same parameterization for convection, clouds and precipitation, observations from the Global Precipitation Climatology Project (GPCP) were used instead of ERA-Interim data for comparison with reality. GPCP is part of the Global Energy and Water Cycle Exchanges (GEWEX) project by the World Climate Research Program (WCRP). The data consists of merged data from gauge stations and satellite data from 1979 to 2018 (Huffman et al., 2009). For comparison with FOCI2, the GPCP dataset was regridded onto a $1.125^{\circ} \times 1.125^{\circ}$ grid with bilinear interpolation. 


\subsection{Methodology}

CDO (Climate Data Operators, Schulzweida, 2019) were used to select variables and time periods, to regrid data, to calculate seasonal variance and means and to apply 2-8 days bandpass-filtering to FOCI2-OpenIFS and ERA-Interim data.

The climatology was determined by calculating multi-year (seasonal) means of seasurface temperature (SST), mean sea-level pressure (MSLP), Atlantic zonal mean of zonal wind $(u)$ and precipitation. These were compared to reanalysis data (Fig. $2,3,4)$ or GPCP observations respectively (Fig. 5).

Bandpass-filtering of MSLP, meridional wind $(v)$ and temperature $(T)$ was used to identify storm activity in an Eulerian approach:

Bandpass-filtering of MSLP data allows for easy computation and reproduction while representing the storm track activity and their interactions with the large scale circulation in accordance with transient eddy variance, spatially filtered statistics, cyclone and precipitation anomalies (Chang, 2009). For the seasonal variance of MSLP, MSLP was detrended, the 29th February deleted, a 2-8 days bandpass-filter applied and yearly seasonal variance calculated (Fig. 6).

Meridional heat flux $\left(\overline{v^{\prime} T^{\prime}}\right)$ is closely linked to mid-latitude storm activity (Raphael, 1997). It was calculated by multiplying $2-8$ days bandpass-filtered $850 \mathrm{hPa} v$ and $T$ data (Fig. 8). In addition, 2-8 days bandpass-filtering of precipitation was used to identify precipitation variance on a synoptic scale (Fig. 7).

A NAO-like (North Atlantic Oscillation) index was extracted from the MSLP anomalies by calculating the leading Empirical Orthogonal Function (EOF1, Fig. 9) of MSLP and its first Principal Component Time Series (PC1, Fig. 10) with the python EOF package by Dawson (2016) for the region of $20-90^{\circ} \mathrm{N}$ and $80^{\circ} \mathrm{W}-40^{\circ} \mathrm{E}$. PC1 was scaled by dividing EOF1 by the square-root of its eigenvalue (Dawson, 2016). Compared to the station-based NAO index, it has the advantage of capturing the moving center of NAO at every time of the year and including less noise from small-scale meteorological phenomena (Hurrell, last modified: 14th Aug. 2020). Also, the linear regression of heat flux onto PC1 was calculated and regions of regions of a significance level of $\mathrm{p}<005$ identified (Fig. 11).

In addition to the Eulerian methods (bandpass-filtering of MSLP and heat flux) to analyse storm regions, a Lagrangian feature tracking algorithm to identify storm tracks by Hodges $(1995,1999)$ and Hoskins and Hodges (2002) was used. 12-hourly 
MSLP data from November to March was extracted for every year in FOCI-standard and FOCI-nest. Then the tracking algorithm was applied. It starts with a spectral filter to isolate the synoptic scale field and a tapering filter. Then MSLP minima are identified and linked together using a nearest-neighbour method and minimizing a cost function to optimize track smoothness. This produces data files of track points for every storm that lasts longer than 2 days and moves farther than $10^{3} \mathrm{~km}$ (Hoskins and Hodges, 2019a).

In order to calculate storm density, storm track points per $2^{\circ} \times 2^{\circ}$ area were counted and normalized by area size $(A)$ to account for the size dependency of latitude. The Earth with radius $r_{\text {Earth }}=6371 \mathrm{~km}$ is approximated as a sphere that is defined by $r^{2}=f(x)^{2}+x^{2}$. In general, surfaces of revolution are calculated with:

$$
A=2 \pi \int_{0}^{h} f(x) \sqrt{1+f^{\prime}(x)^{2}} d x, \quad f(x)=\sqrt{r^{2}-x^{2}}
$$

This leads to:

$$
A=2 \pi \int_{0}^{h} \sqrt{r^{2}-x^{2}} \sqrt{1+\left(\frac{-x}{r^{2}-x^{2}}\right)^{2}} d x=2 \pi r h, \quad h=r(1-\sin (l a t))
$$

Therefore the size of one $2^{\circ} \times 2^{\circ}$ area dependent on its southern latitude has the size:

$$
A_{2^{\circ} \times 2^{\circ}}\left(\text { lat }_{\text {south }}\right)=\frac{2^{\circ}}{360^{\circ}}\left(A_{\text {lat }_{\text {south }}}-A_{\text {lat }_{\text {north }}}\right)=\frac{\pi r_{\text {Earth }}^{2}}{90}\left(\sin \left(\text { lat }_{\text {south }}+2^{\circ}\right)-\sin \left(\text { lat }_{\text {south }}\right)\right)
$$

This was used to calculate overall storm, storm genesis, and storm lysis density as the number of track points per $10^{4} \mathrm{~km}^{2}$ and NDJFM (November-March) period (Fig. 12). For this thesis, a storm genesis track point is defined as the first and a storm lysis track point is defined as the last track point of a given storm track.

Mean growth and decay rates were calculated as the sum of magnitude differences between the next and the current track point belonging to one common track divided by the number of track points in this area. Mean intensity was calculated as the sum of magnitudes divided by the number of track points in this area. Mean lifetime was calculated by assigning half (because of 12-hourly data) of the number of track points in the respective storm to every track point, adding them up in every $2^{\circ} \times 2^{\circ}$ area and dividing them by the number of track points in this area (Fig. 13). 


\section{Results}

Applying the methods described in the previous section to FOCI-standard, FOCInest, ERA-Interim reanalysis and GPCP data led to the following results:

Comparability of FOCI-standard and FOCI-nest in spite of their short spin-up time was examined by comparing mean North Atlantic sea-surface temperature (SST) in a box of $40-60^{\circ} \mathrm{N}$ and $20-40^{\circ} \mathrm{W}$ as a function of time (Fig. 1). Yearly mean SST is 1.5-3.5 K higher in FOCI-nest than in FOCI-standard. The standard deviation of yearly mean SST is similar for FOCI-standard $(0.36 \mathrm{~K})$ and FOCI-nest $(0.35 \mathrm{~K})$. But in the case of FOCI-nest this can be ascribed to a strong warming trend of $2.35 \mathrm{~K} /$ century, while FOCI-standard is nearly constant with a warming trend of $0.28 \mathrm{~K} /$ century. Therefore, FOCI-nest has not reached the equilibrium in 1850-conditions. This should be considered when comparing the climatology of the models. However, yearly mean SST of FOCI-nest is closer to reanalysis data. In the reanalysis SST increases by $1.19 \mathrm{~K} /$ century and has a standard deviation of $0.42 \mathrm{~K}$.

It is to be noted that the region of $40-60^{\circ} \mathrm{N}$ and $20-40^{\circ} \mathrm{W}$ is not necessarily representative for the whole North Atlantic region.

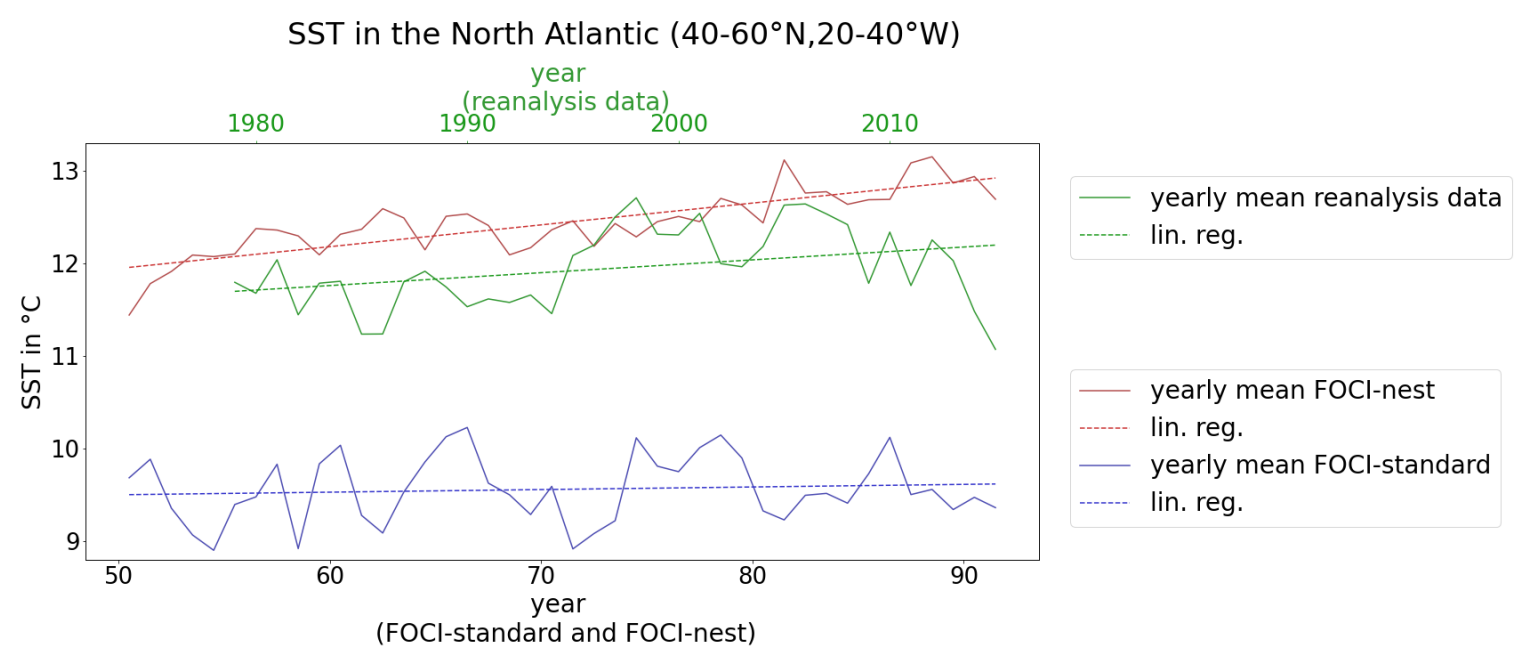

Figure 1: Yearly North Atlantic $\left(40-60^{\circ} \mathrm{N}, 20-40^{\circ} \mathrm{W}\right)$ mean SST in ${ }^{\circ} \mathrm{C}$ of FOCIstandard (blue) and FOCI-nest (red) from model year 50 to 91 and of reanalysis data (green) from 1979 to 2015 and the respective linear regressions (dotted lines) 


\subsection{Model Climatology and Bias}

In the following, climatology extracted from FOCI-standard and FOCI-nest data is compared to climatology from ERA-Interim reanalysis and GPCP data. For this purpose reanalysis data and GPCP data were regridded to the atmospheric horizontal resolution of OpenIFS $\left(1.125^{\circ}\right)$.

In comparison to reanalysis data, FOCI-standard underestimates sea-surface temperature (SST) by up to $7 \mathrm{~K}$ in the central North Atlantic at around $48^{\circ} \mathrm{N}$ and $40^{\circ} \mathrm{W}$ and overestimates SST close to the North American coast at around $40^{\circ} \mathrm{N}$. Additionally, it shows a positive bias of up to $4 \mathrm{~K}$ southwest of Svalbard (Fig. 2, middle). FOCI-nest is generally warmer than FOCI-standard in the central North Atlantic and colder on the east coast of North America and southwest of Svalbard (Fig. 2, left). This leads to a warm bias of $1-2 \mathrm{~K}$ in most of the North Atlantic compared to the reanalysis but limits the formerly $7 \mathrm{~K}$ SST cold bias to $4 \mathrm{~K}$ and reduces the warm biases at the North American coast and southwest of Svalbard. Locally, the warm bias in the Labrador Sea is increased to up to $3 \mathrm{~K}$ (Fig. 2, right).

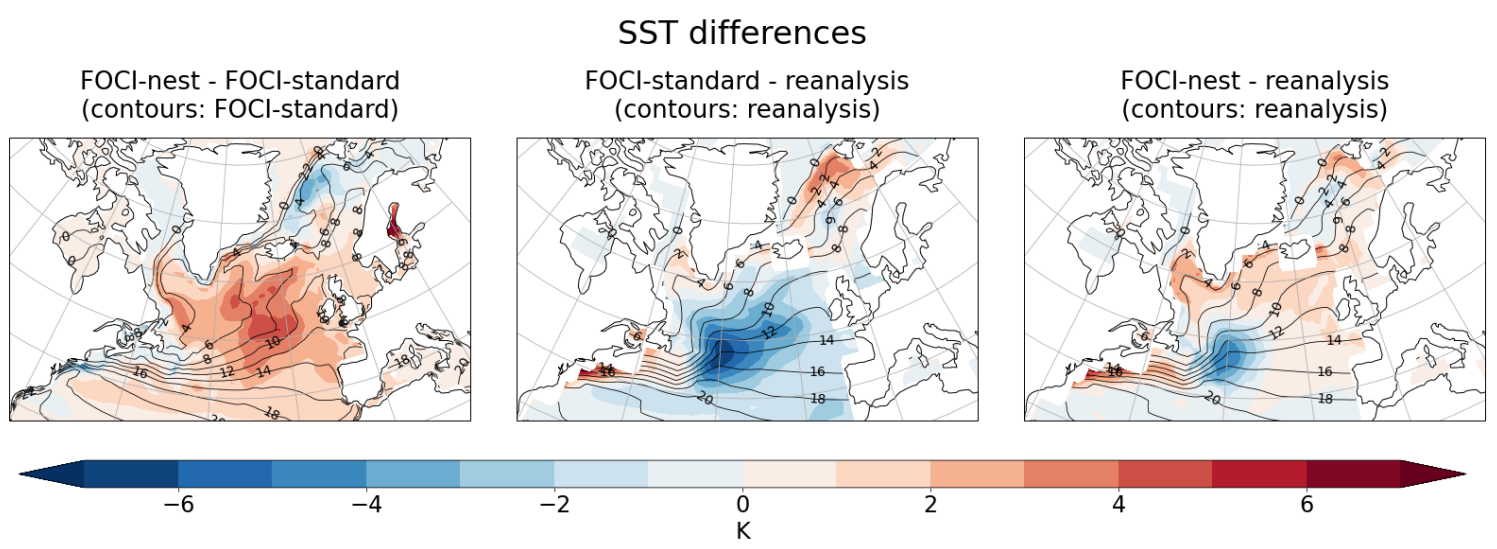

Figure 2: Differences of FOCI-nest and FOCI-standard (left), of FOCI-standard and reanalysis data (middle) and of FOCI-nest and reanalysis data (right) mean SST in K; FOCI-standard (left) and reanalysis data (middle, right) mean SST in K as contours; time period: FOCI: model years 50-91, reanalysis: 1979-2015

The atmospheric response to the ocean depends on the state of the sea-surface. So a change in SST likely impacts the atmosphere. Based on the reduction of the SST biases, the impact of ocean resolution on the atmosphere is studied by looking at mean sea-level pressure (MSLP), zonal wind $(u)$ and precipitation in FOCI-standard and FOCI-nest and their biases: 

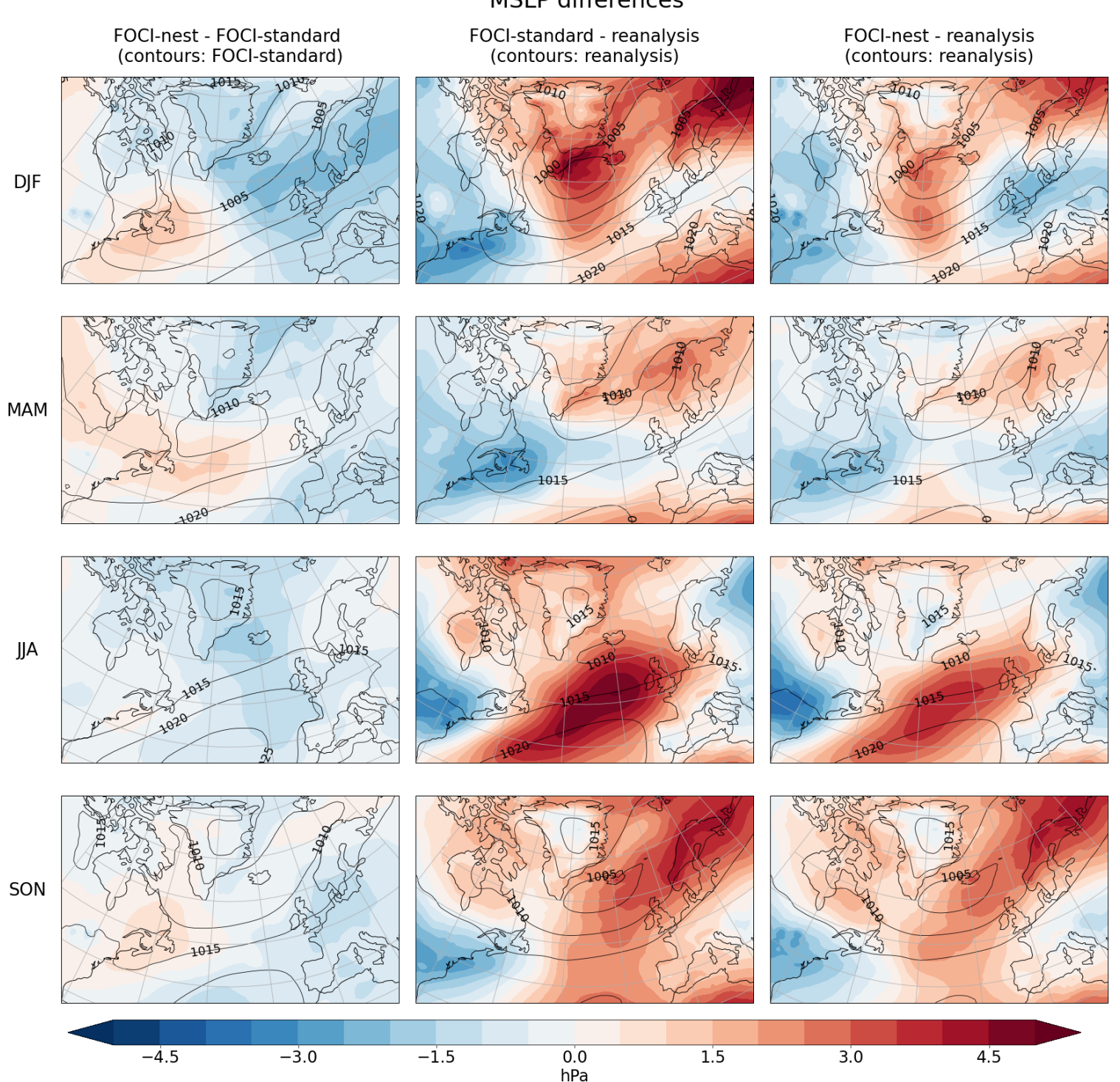

Figure 3: Differences of FOCI-nest and FOCI-standard (1st column), of FOCIstandard and reanalysis data (2nd column) and of FOCI-nest and reanalysis data (3rd column) multiyear seasonal mean MSLP in hPa; FOCI-standard (1st column) and reanalysis data (2nd, 3rd column) multiyear seasonal mean MSLP in hPa as contours; time period: FOCI: model years 50-91, reanalysis: 1979-2013 


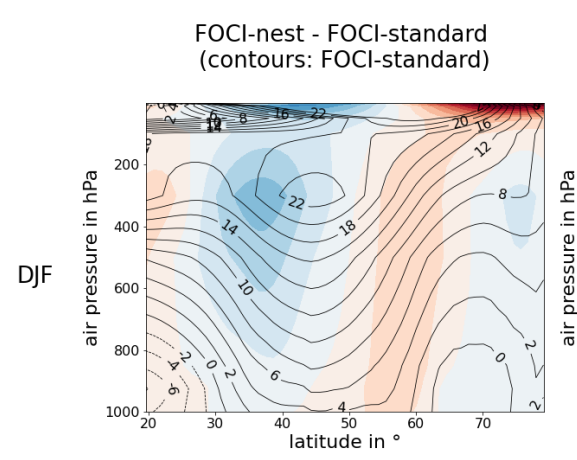

Zonal mean $u$ differences
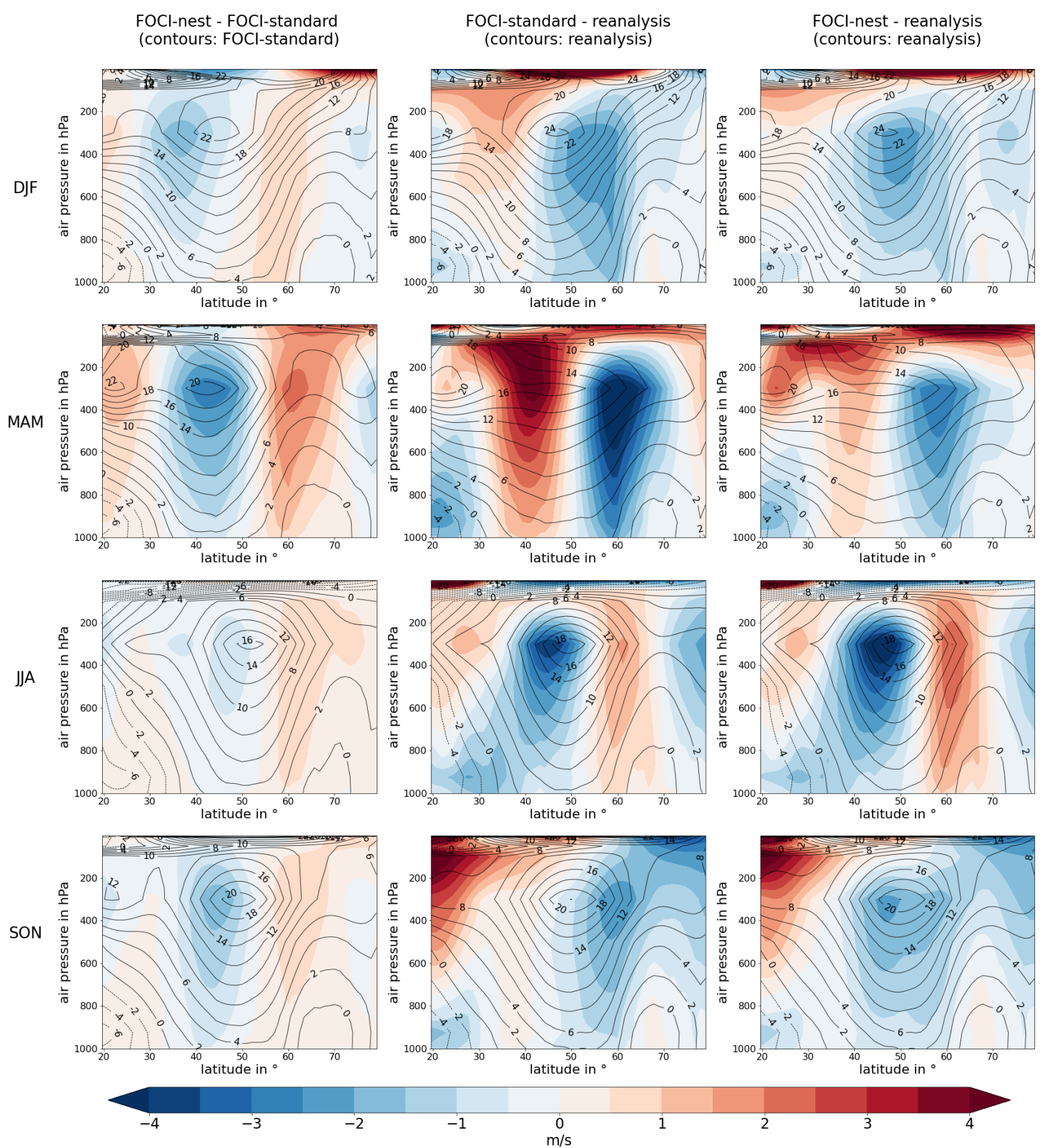

Figure 4: Differences of FOCI-nest and FOCI-standard (1st column), of FOCIstandard and reanalysis data (2nd column) and of FOCI-nest and reanalysis data (3rd column) multiyear seasonal North Atlantic $\left(20-80^{\circ} \mathrm{N}\right)$ zonal mean $\left(60-0^{\circ} \mathrm{W}\right)$ of zonal wind component $(u)$ in $\mathrm{m} / \mathrm{s}$; FOCI-standard (1st column) and reanalysis data (2nd, 3rd column) multiyear seasonal North Atlantic $\left(20-80^{\circ} \mathrm{N}\right)$ zonal mean $(60-$ $0^{\circ} \mathrm{W}$ ) of zonal wind component $(u)$ in $\mathrm{m} / \mathrm{s}$ as contours; time period: FOCI: model years 50-91, reanalysis: 1979-2016 
In general the MSLP biases of FOCI-standard are smaller in FOCI-nest, except for a negative bias over central Europe in DJF (December-February, Fig. 3, 3rd column) which did not occur in FOCI-standard. In comparison to reanalysis data, FOCIstandard underestimates mean MSLP close to the North American coast, matches MSLP at western central Europe and overestimates MSLP in the Arctic Ocean, the central North Atlantic and northern Africa in DJF. The largest positive biases of $\sim 4.5 \mathrm{hPa}$ are located over the southern coast of Greenland and over the Barents Sea. Therefore, FOCI-standard does not display the winter mean MSLP minimum of less than $1000 \mathrm{hPa}$ south of Greenland, which is prominent in the reanalysis. In MAM (March-May) the MSLP differences are much smaller than in DJF and limited to $\pm 3 \mathrm{hPa}$. The distribution of MSLP differences is similar in both seasons. In JJA (June-August) a strong positive bias of $\sim 4.5 \mathrm{hPa}$ appears at around $50^{\circ} \mathrm{N}$ in the central North Atlantic spreading north across Greenland and Canada. Eastern Europe and southern North America show small negative biases. In SON (September-November) FOCI-standard has a strong positive bias to the reanalysis in northern Europe and the Arctic Ocean and a positive bias in the central North Atlantic at around $20^{\circ} \mathrm{W}$. It shows a small negative bias in North America and matches MSLP over Greenland (Fig. 3, 2nd column).

In the following, Atlantic $\left(20-80^{\circ} \mathrm{N}\right)$ zonal mean $\left(60-0^{\circ} \mathrm{W}\right) u$ of FOCI-standard and FOCI-nest is compared with the reanalysis by interpolating all data to the same horizontal grid and 10 irregularly spaced atmospheric pressure levels.

North Atlantic zonal mean $u$ biases of FOCI-standard are strongest in MAM with a positive bias of $\sim 5 \mathrm{~m} / \mathrm{s}$ around the $100 \mathrm{hPa}$ level at $40^{\circ} \mathrm{N}$ and a negative bias of $\sim-6 \mathrm{~m} / \mathrm{s}$ around the $300 \mathrm{hPa}$ level at $60^{\circ} \mathrm{N}$ which implies that the wind maximum is too high and too far south in the model. DJF shows a similar pattern of zonal mean $u$ with smaller biases and a clearer differentiation of the polar jet stream at around $45^{\circ} \mathrm{N}$ compared to MAM (Fig. 4, 2nd column). In JJA the jet is too far north in FOCI-standard but located on the same height as in the reanalysis. In SON the jet is too far south in FOCI-standard in comparison to the reanalysis. Around $100 \mathrm{hPa}$ at $20^{\circ} \mathrm{N}$ a strong positive bias of more than $4 \mathrm{~m} / \mathrm{s}$ appears (Fig. 4, 2nd column).

Zonal mean $u$ biases are reduced in FOCI-nest compared to FOCI-standard in DJF and MAM due to a northward shift of the modelled jet stream (Fig. 4, 1st column). In $\mathrm{SON}$ the biases in FOCI-nest to the reanalysis are increased by up to $1 \mathrm{~m} / \mathrm{s}$ locating the jet stream even further northward than the low resolution model. In SON in 


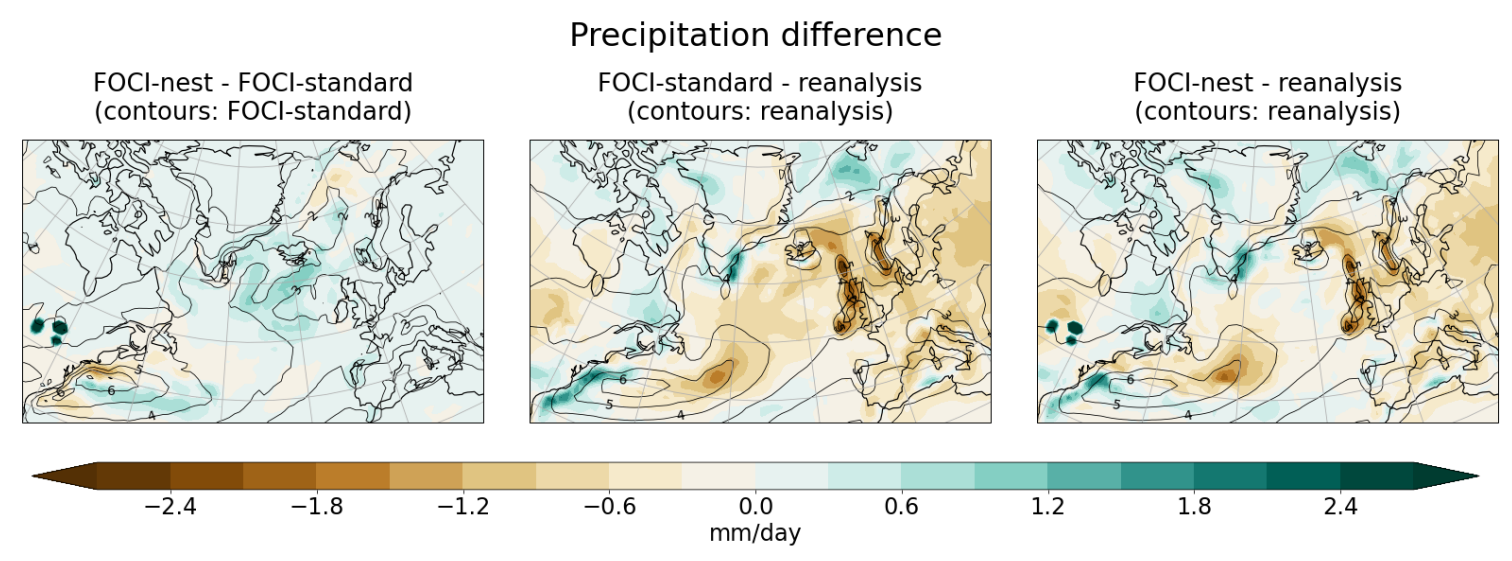

Figure 5: Differences of FOCI-nest and FOCI-standard (left), of FOCI-standard and GPCP data (middle) and of FOCI-nest and GPCP data (right) mean precipitation in $\mathrm{mm}$ /day; FOCI-standard (left) and GPCP data (middle, right) mean precipitation as contours; time period: FOCI: model years 50-91, GPCP observations: 1979-2018

FOCI-nest the biases in location of the jet stream are reduced but a negative bias in magnitude appears compared to FOCI-standard. The positive bias in the southern upper troposphere resembles the one in FOCI-standard (Fig. 4, 3rd column).

Precipitation is generally slightly higher in FOCI-nest than in FOCI-standard. It increases over the Gulf Stream at around $48^{\circ} \mathrm{N}$ and decreases north and south of it in FOCI-nest compared to FOCI-standard. Additionally, it is lower in FOCI-nest than in FOCI-standard southwest and west of Svalbard. In comparison to GPCP data, FOCI-standard has a negative bias over Europe peaking with $\sim-2.4 \mathrm{~mm} /$ day over the west coast of Ireland and Great Britain. The largest positive biases are at the eastern coast of southern Greenland and south of $50^{\circ} \mathrm{N}$ on the North American coast. Additionally, FOCI-standard underestimates precipitation over the Arctic Ocean. In FOCI-nest the negative biases over Europe and the central North Atlantic are smaller than in FOCI-standard, whereas the positive biases are similar to the ones of FOCI-standard.

The high precipitation values in FOCI-nest at the location of the Great Lakes in North America were noticed. The reason for these bias appearances in FOCI-nest compared to FOCI-standard is beyond the scope of this thesis. 


\subsection{Variability}

The Eulerian approach uses bandpass-filtered MSLP on a synoptic time scale (2-8 days) as indications of storm activity (Fig. 6). 2-8 days bandpass-filtered precipitation is used as a measure for synoptic scale precipitation variance (Fig. 7).

Seasonal variance of 2-8 days bandpass-filtered 12-hourly MSLP data in the reanalysis is strongest over the coast of North America at around $50^{\circ} \mathrm{N}$ in DJF with $\sim 76(\mathrm{hPa})^{2}$. The further east in the Atlantic, the further north the highest values for each longitude are found. FOCI-standard shows a positive bias of $\sim 26(\mathrm{hPa})^{2}$ close to the North American coast at around $55^{\circ} \mathrm{N}$ spreading north- and eastward. In MAM seasonal variance of MSLP peaks at $\sim 42(\mathrm{hPa})^{2}$ in a similar location as in DJF in the reanalysis. The biases of FOCI-standard are between 10 and $15(\mathrm{hPa})^{2}$ spreading east across the Atlantic from the North American coast at around $50^{\circ} \mathrm{N}$. In JJA and SON seasonal variance of MSLP peaks at $\sim 23(\mathrm{hPa})^{2}$ and at $\sim 53(\mathrm{hPa})^{2}$, respectively. The biases are limited to $10(\mathrm{hPa})^{2}$.

FOCI-nest shows a MSLP variance bias of $\sim 21(\mathrm{hPa})^{2}$ in DJF which is smaller than in FOCI-standard. At around $10-30^{\circ} \mathrm{W}$ the positive biases are increased in FOCInest compared to the ones in FOCI-standard from the west coast of Ireland to the east coast of Greenland. In MAM the local positive bias maximum across the North Atlantic is reduced in FOCI-nest compared to FOCI-standard. However, the positive bias in the Barents Sea is larger in FOCI-nest leading to a small overall positive bias in the North Atlantic region in FOCI-nest. In JJA and SON, the model differences and biases are weak.

In general MSLP variance biases in both models are smaller in SON than in MAM despite the absolute MSLP variance being higher in SON. This suggests that the models simulate storms better in SON than in MAM.

The variance of precipitation on a 2-8 days synoptic time scale is generally slightly higher in FOCI-nest than in FOCI-standard. It differs most at the east coast of southern Greenland and at around $38^{\circ} \mathrm{N}$ in the western North Atlantic. Close to the North American coast and at around $32^{\circ} \mathrm{N}$ and $50^{\circ} \mathrm{N}$, bandpass-filtered precipitation is higher in FOCI-standard than in FOCI-nest in the western North Atlantic. 


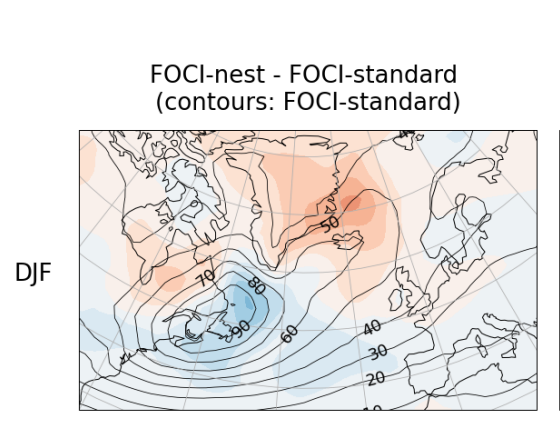

\section{MSLP variance differences}

FOCl-standard - reanalysis (contours: reanalysis)
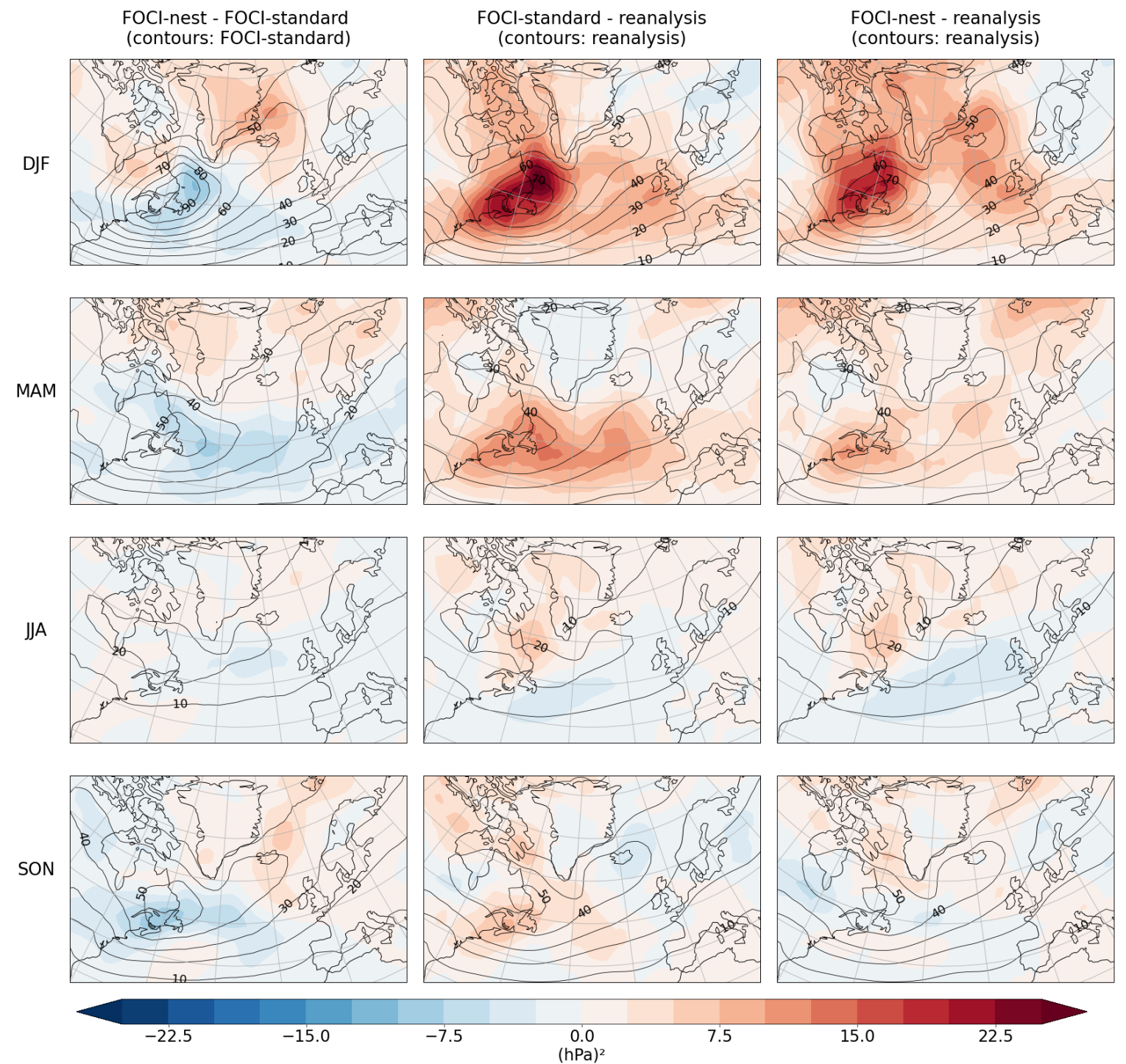

Figure 6: Differences of FOCI-nest and FOCI-standard (1st column), of FOCIstandard and reanalysis data (2nd column) and of FOCI-nest and reanalysis data (3rd column) multiyear seasonal variance of MSLP in (hPa) ${ }^{2}$; FOCI-standard (1st column) and reanalysis data (2nd, 3rd column) multiyear seasonal variance of MSLP in $(\mathrm{hPa})^{2}$ as contours; time period: FOCI: model years 50-91, reanalysis: 1979-2014 


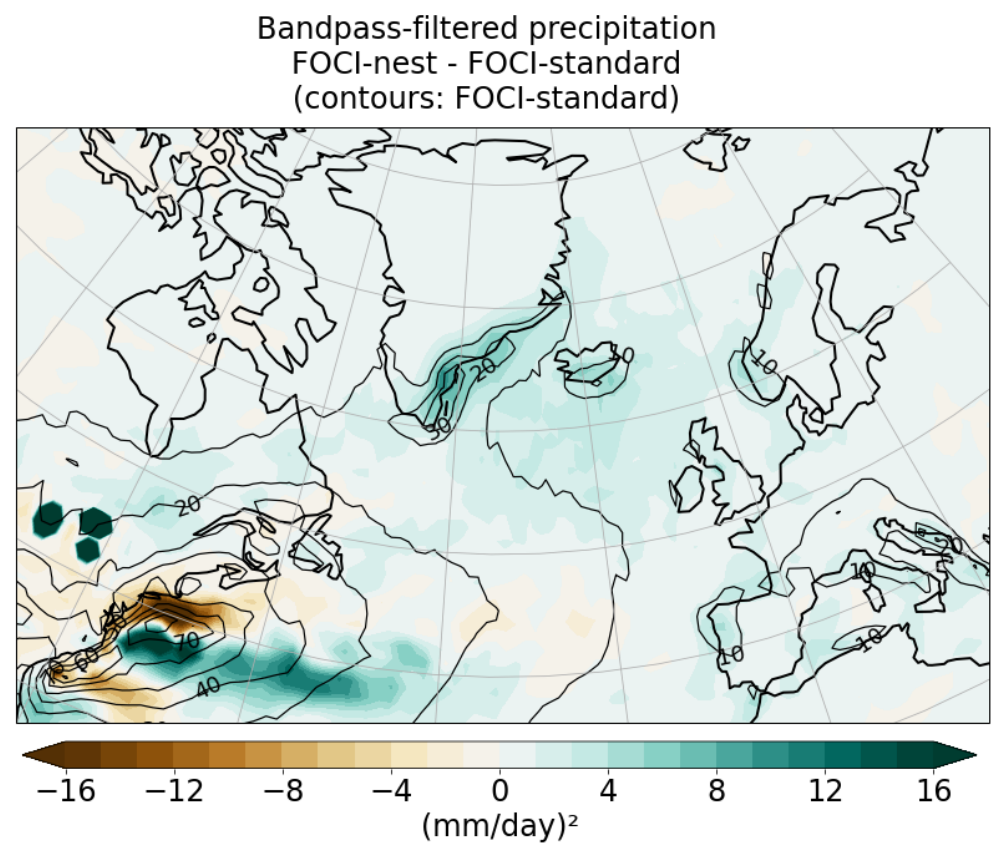

Figure 7: Difference of FOCI-nest and FOCI-standard multiyear mean 2-8 days bandpass-filtered precipitation in $(\mathrm{mm} / \text { day })^{2}$, time period: model years $50-91$

\subsection{Heat Flux and North Atlantic Oscillation}

The meridional eddy heat flux $\left(\overline{v^{\prime} T^{\prime}}\right.$, Fig. 8) was calculated as the covariance of 2-8 days bandpass-filtered $850 \mathrm{hPa}$ meridional wind $(v)$ and temperature $(T)$. Meridional eddy heat flux in FOCI-standard is strongest in winter east of the North American coast with $\sim 25 \mathrm{~K} \mathrm{~m} / \mathrm{s}$ at around $47^{\circ} \mathrm{N}$ and $60^{\circ} \mathrm{W}$. In MAM a similar pattern occurs with a maximum of $\sim 16 \mathrm{~K} \mathrm{~m} / \mathrm{s}$. In JJA the maximal heat flux is limited to $\sim 12 \mathrm{~K} \mathrm{~m} / \mathrm{s}$ and shifted northwestward to $55^{\circ} \mathrm{N}$ and $65^{\circ} \mathrm{W}$. In SON the heat flux is higher than in JJA and its maximum $(\sim 16 \mathrm{~K} \mathrm{~m} / \mathrm{s})$ shifts southeastward to around $48^{\circ} \mathrm{N}$ and $55^{\circ} \mathrm{W}$.

North of $55^{\circ} \mathrm{N}$, FOCI-nest generally shows higher heat fluxes than FOCI-standard but south of $55^{\circ} \mathrm{N}$ this relation is reversed. This implies more storm activity to the north and less to the south (Fig. 8). The largest difference between FOCI-standard and FOCI-nest occurs in DJF in the Labrador Sea, where eddy heat flux is $3 \mathrm{~K} \mathrm{~m} / \mathrm{s}$ stronger in FOCI-nest. Additionally, eddy heat flux is stronger in FOCI-nest around Iceland in SON and DJF. In MAM this difference is located further south $\left(60^{\circ} \mathrm{N}\right)$ and in JJA it disappears. The largest negative difference of $\sim-2 \mathrm{~K} \mathrm{~m} / \mathrm{s}$ is found in SON and DJF. In SON this difference is found at around $50^{\circ} \mathrm{N}$ spreading from 


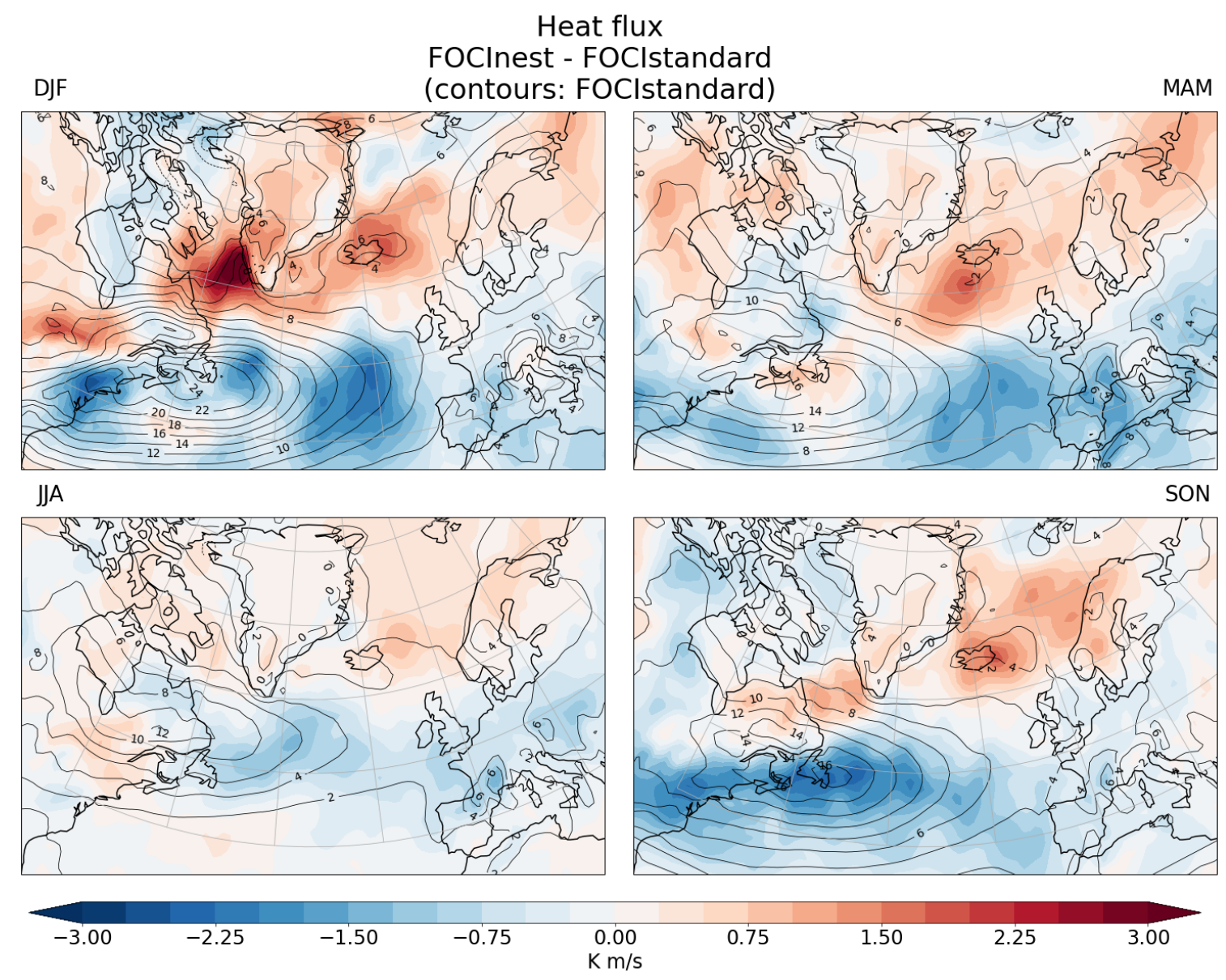

Figure 8: Difference of FOCI-nest and FOCI-standard multiyear seasonal heat flux in $\mathrm{K} \mathrm{m} / \mathrm{s}$; multiyear seasonal heat flux of FOCI-standard in $\mathrm{K} \mathrm{m} / \mathrm{s}$ as contours; heat flux calculated as product of 2-8 days bandpass-filtered $850 \mathrm{hPa}$ meridional wind $(v)$ and temperature $(T)$; time period: model years $50-91$

the coast of North America to approximately $30^{\circ} \mathrm{W}$. In DJF FOCI-nest differs from FOCI-standard at around $45^{\circ} \mathrm{N}$ both on the North American coast and at around $30^{\circ} \mathrm{W}$. In MAM the biggest negative difference is found over southern Europe and the eastern Atlantic at around $47^{\circ} \mathrm{N}$ and $20^{\circ} \mathrm{W}$ (Fig. 8).

The leading Empirical Orthogonal Function (EOF1) of MSLP represents the dominant pattern of its variance. It accounts for $37 \%$ of the MSLP variance in FOCIstandard, $41 \%$ in FOCI-nest and $43 \%$ in the reanalysis. The pattern is similar in FOCI-standard, FOCI-nest and the reanalysis with negative correlation coefficients over Greenland and positive correlation coefficients at around $40^{\circ} \mathrm{N}$ (Fig. 9). However, the curve of the level of no correlation and the magnitude of the correlation coefficient differ. In FOCI-standard the positive correlation is aligned to the south- 


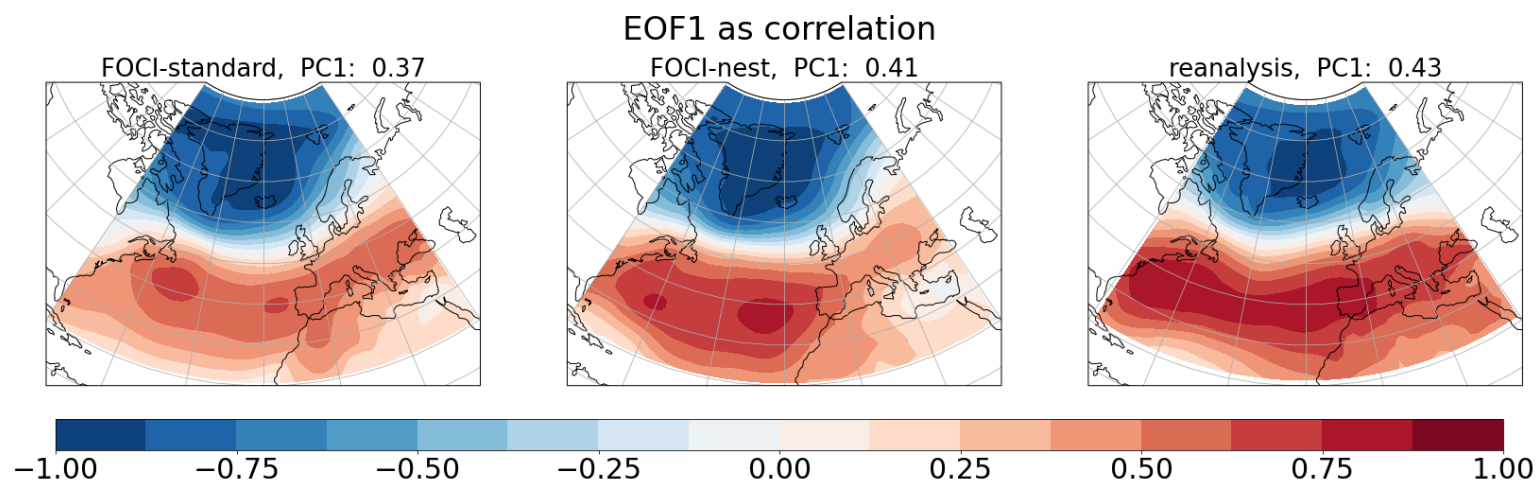

Figure 9: EOF1 as correlation between PC1 and MSLP anomalies over the North Atantic region $\left(20-90^{\circ} \mathrm{N}\right.$ and $\left.80^{\circ} \mathrm{W}-40^{\circ} \mathrm{E}\right)$ in DJF of FOCI-standard (left), FOCInest (middle) and reanalysis data (right); time period: FOCI: model years 50-91, reanalysis: 1979-2013
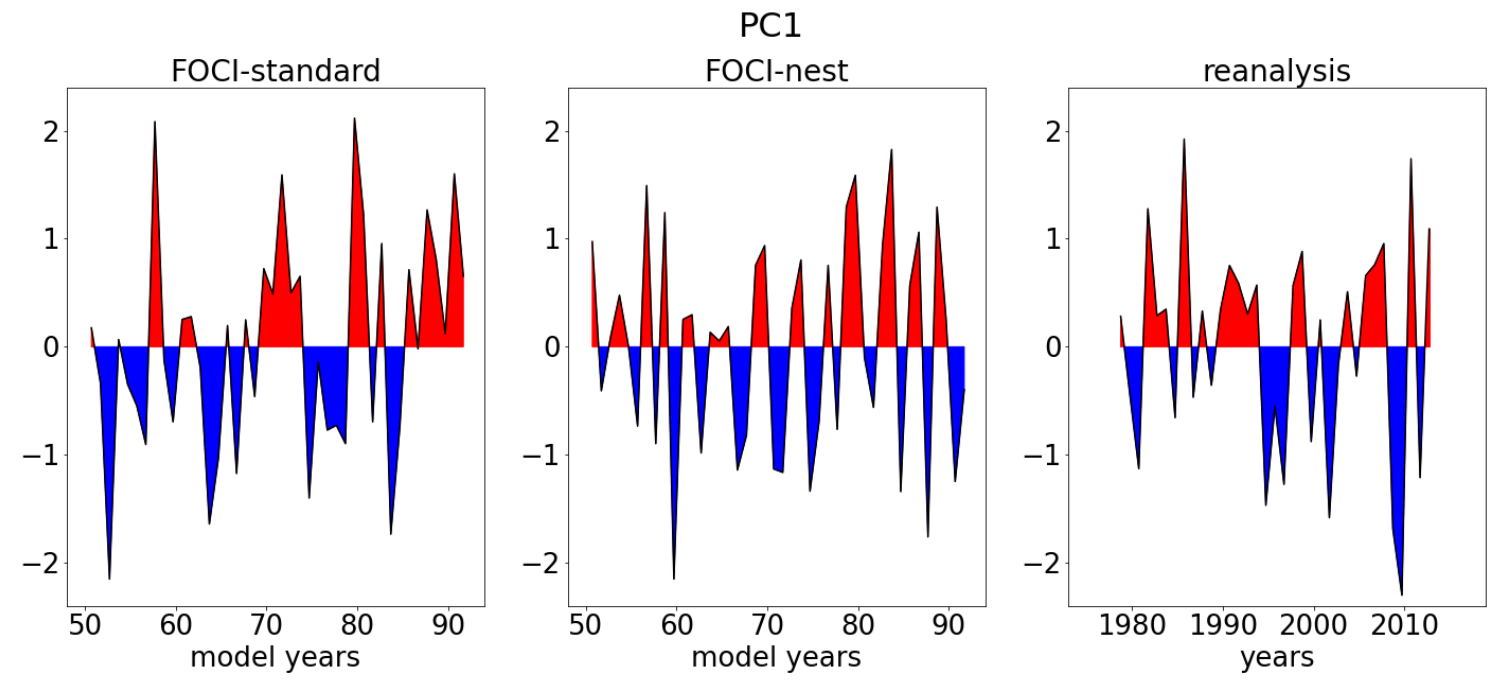

Figure 10: Scaled PC1 of MSLP as index for NAO of FOCI-standard (left), FOCInest (middle) and reanalysis data (right); time period: FOCI: model years 50-91, reanalysis: 1979-2013

east North American coast and has a zonal course eastward through the Atlantic at $50-55^{\circ} \mathrm{N}$ with a tilt to higher latitudes over Europe. Additionally, the positive correlation is stronger in FOCI-nest than in FOCI-standard over the North Atlantic at around $38^{\circ} \mathrm{N}$ with a sharper land-sea-contrast. The negative correlation over Greenland is in better accordance with the coastline in FOCI-nest than in FOCIstandard as well. In the reanalysis the region of no correlation shows a different course to the ones of FOCI-standard and FOCI-nest with a curve at around $40^{\circ} \mathrm{W}$ and another at around $20^{\circ} \mathrm{E}$. Therefore, the positive correlation over eastern North 
America increases and the correlation coefficient over northeastern Europe decreases. The positive correlation maximum is nearly zonal at around $40^{\circ} \mathrm{N}$ and the negative correlation coefficient maximum is limited to a smaller region over the west coast of Greenland compared to FOCI-standard and FOCI-nest. When comparing FOCI2 to the reanalysis, the correlation coefficient is higher in eastern North America and Scandinavia in FOCI2. So there is only a weak correlation over Scandinavia in FOCI2, while the correlation is strongly negative in the reanalysis. Also, there is only a weak correlation at the southeast coast of North America in FOCI2 while the correlation is strongly positive in the reanalysis.

The scaled first Principal Component Time Series (PC1) of EOF1 of MSLP anomalies is used as an index for the North Atlantic Oscillation (NAO). It shows an irregular multiyear variability in FOCI-standard and the reanalysis, while in FOCI-nest the variability is very regular with approximately 3-year periods (Fig. 10).

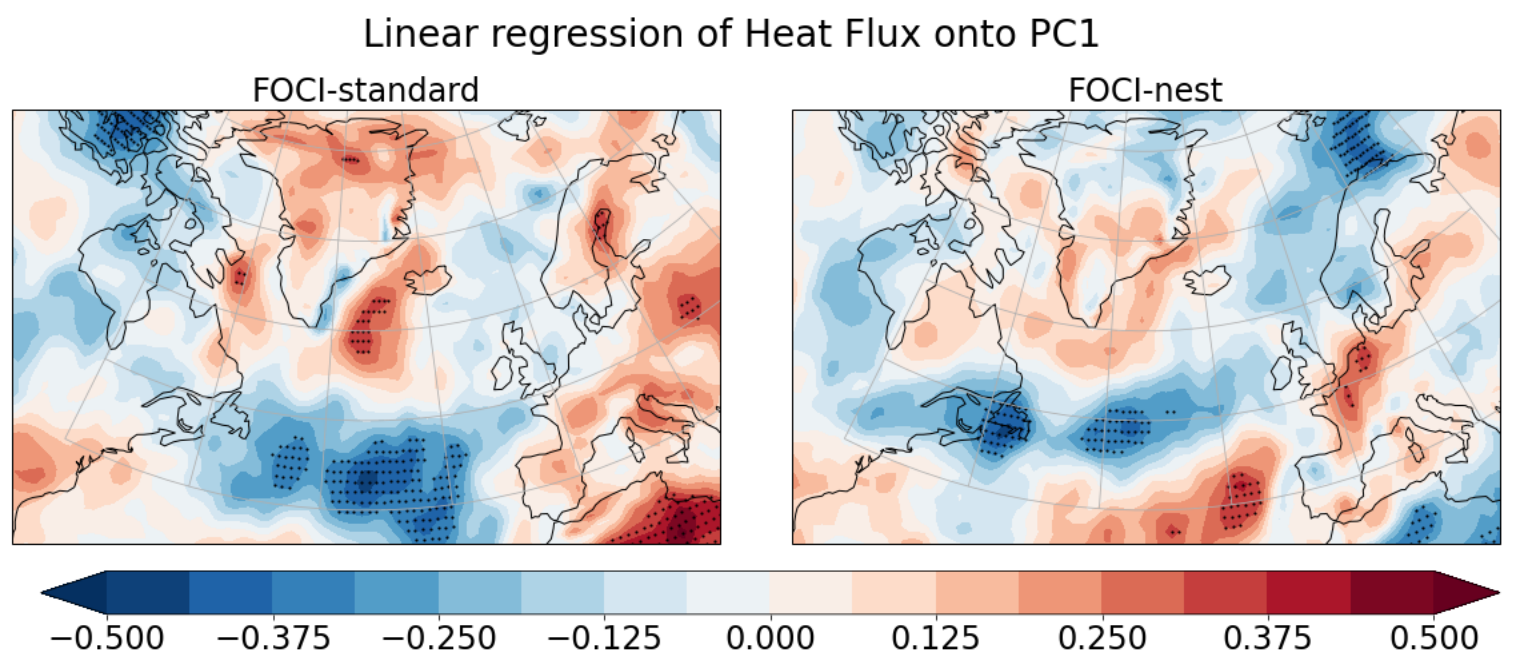

Figure 11: Linear regression of heat flux onto PC1 of FOCI-standard (left) and FOCI-nest (right); $\mathrm{p}<0.05$ in dotted regions; time period: model years 50-91

The linear regression of eddy heat flux onto PC1 in FOCI-standard shows a significantly $(\mathrm{p}<0.05)$ increased heat flux over the Irminger Sea, the Labrador Sea, the northern Baltic Sea, northern Africa and eastern Europe in positive PC1 phases (Fig. 11). In the North Atlantic Ocean at around $45^{\circ} \mathrm{N}$ and in the Canadian Archipelago, the heat flux decreases significantly in positive NAO phases. In FOCI-nest, the linear regression shows an increase in heat flux in positive NAO phases at around $40^{\circ} \mathrm{N}$ and $20^{\circ} \mathrm{W}$ and in northwestern central Europe. Around $50^{\circ} \mathrm{N}$ and at around $25^{\circ} \mathrm{E}$ over the Barents Sea, the heat flux decreases in positive NAO phases. 


\subsection{Lagrangian Storm Tracking}
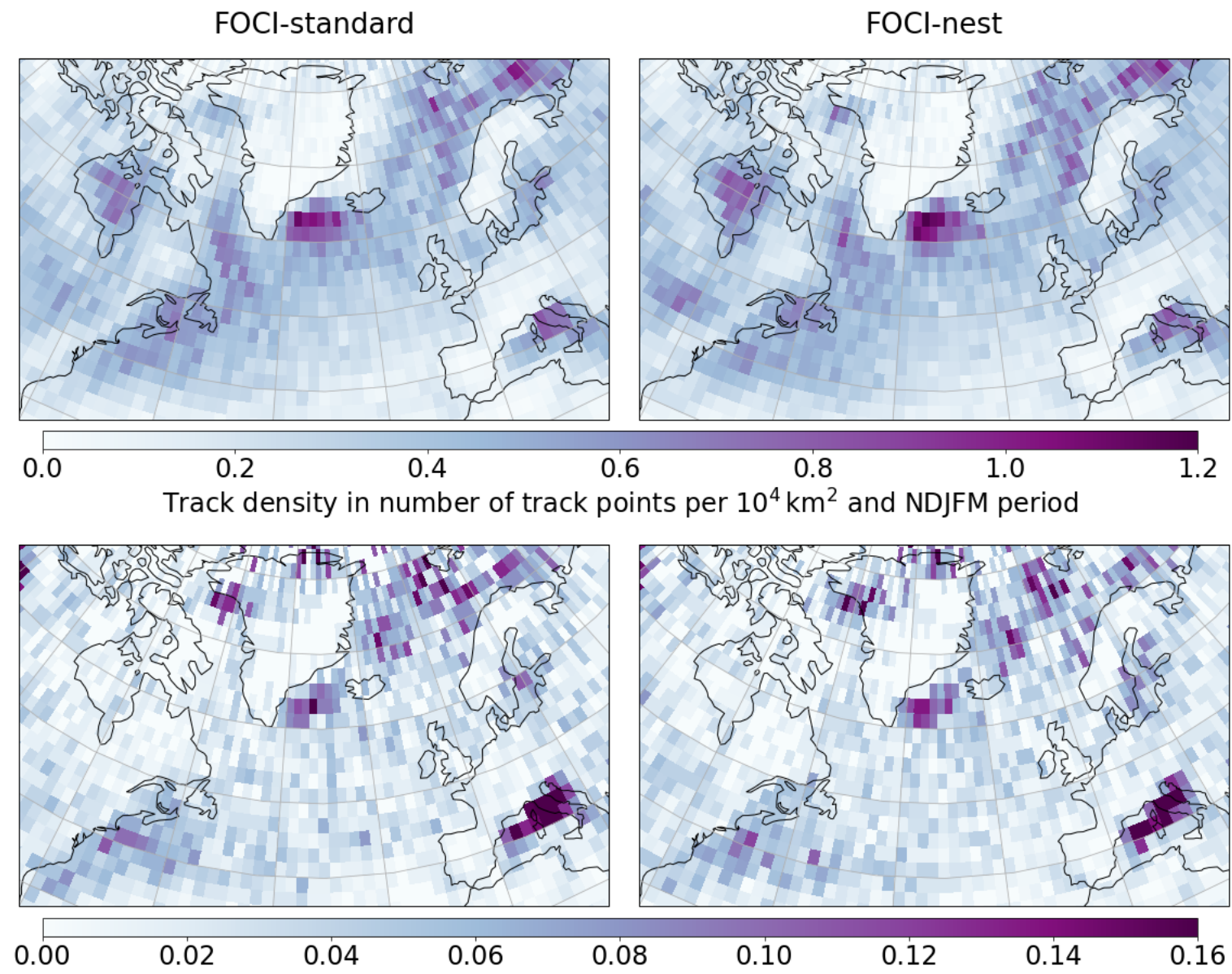

0.10

0.12

0.14

0.16

Genesis density in number of genesis track points per $10^{4} \mathrm{~km}^{2}$ and NDJFM period
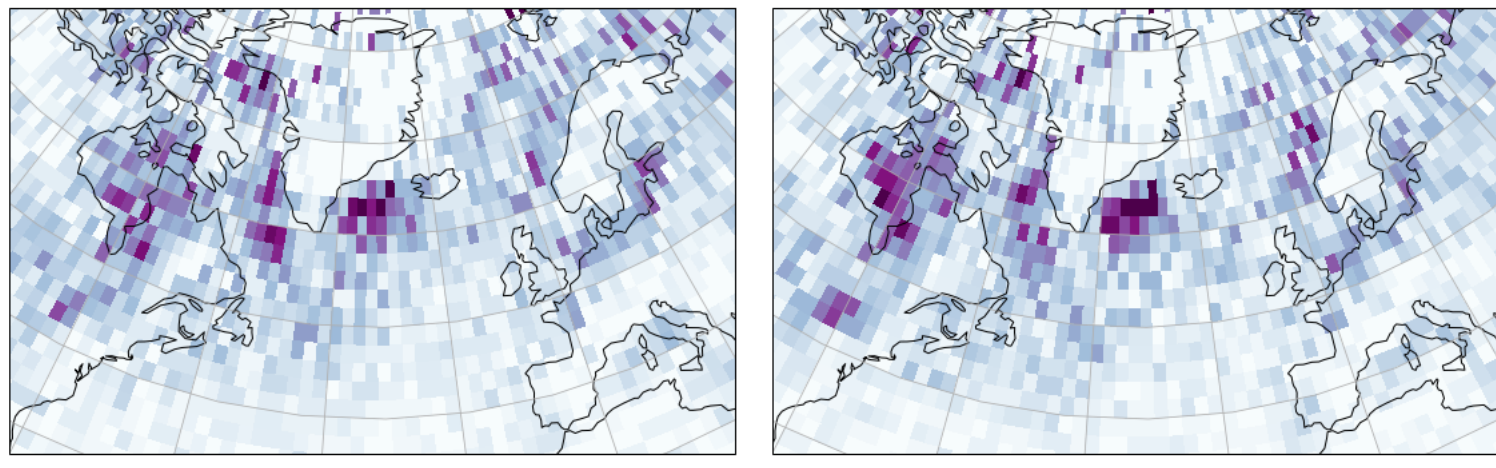

0.00

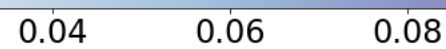

0.10

0.12

0.14

0.16

Lysis density in number of lysis track points per $10^{4} \mathrm{~km}^{2}$ and NDJFM period

Figure 12: Storm track density: number of track points (top), number of storm genesis track points (middle) and number of storm lysis track points (bottom) per $10^{4} \mathrm{~km}^{2}$ and NDJFM period in FOCI-standard (left column) and FOCI-nest (right column), white areas: no track points; time period: model years 50-91 

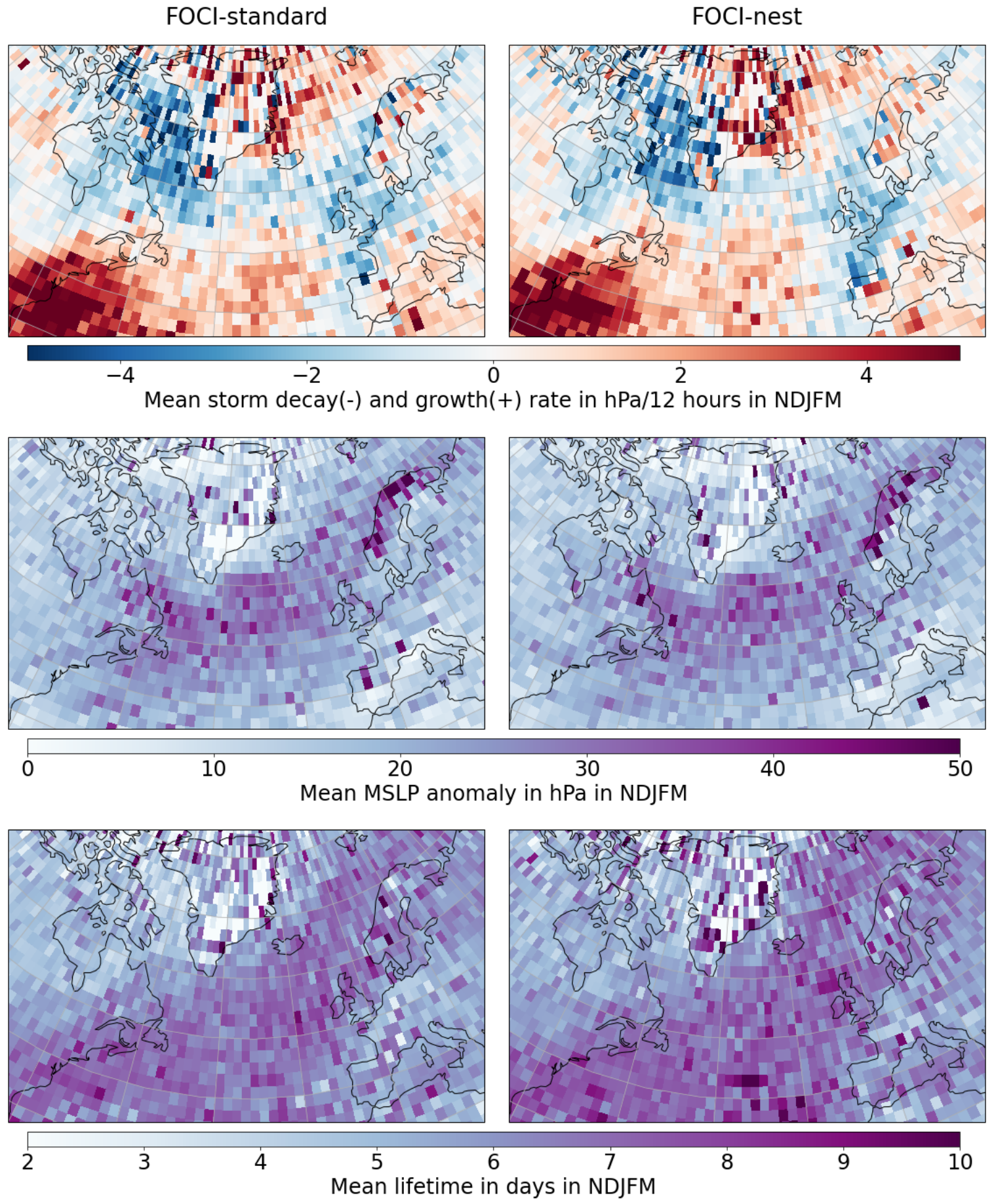

Figure 13: Mean decay (negative) and growth (positive) rate as MSLP anomaly difference to the next storm track point in $\mathrm{hPa} / 12$ hours (top), mean MSLP anomaly of storm track points in $\mathrm{hPa}$ (middle), mean lifetime of storms in days (bottom) in FOCI-standard (left column) and FOCI-nest (right column), white areas: no track points; time period: model years 50-91 

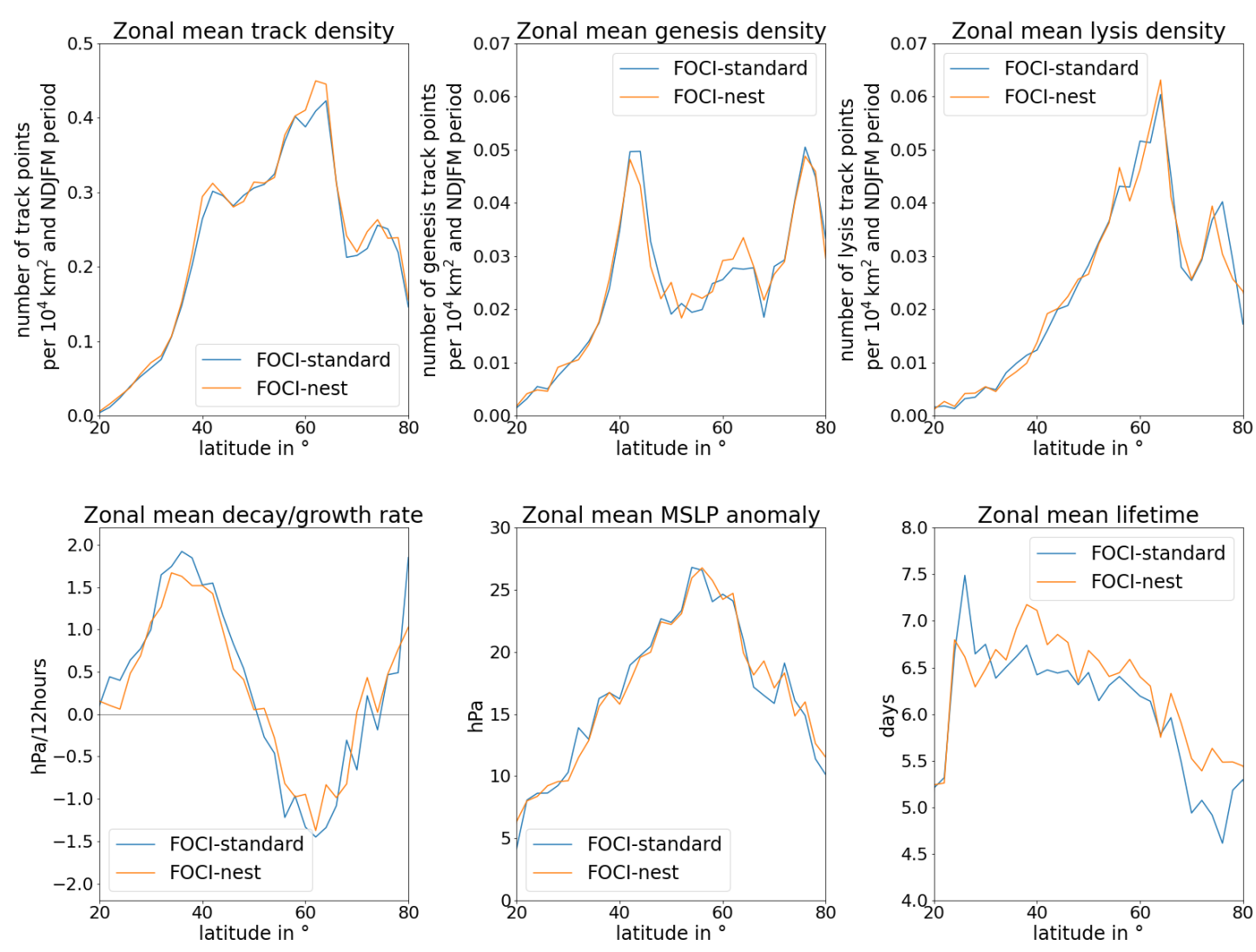

Figure 14: Zonal mean $\left(80^{\circ} \mathrm{W}-20^{\circ} \mathrm{E}\right)$ of features shown in Fig. 12, 13

Individual MSLP minima in FOCI-standard and FOCI-nest were tracked by using the storm tracking algorithm (Hodges, 1995, 1999; Hoskins and Hodges, 2002). Track points of storms that last longer than 2 days and move farther than $10^{3} \mathrm{~km}$ were assigned to the respective $2^{\circ} \times 2^{\circ}$ 2-dimensional-histogram cell.

Track density is calculated from all the storm track points in the output of the storm tracking algorithm. In FOCI-standard and FOCI-nest storm track density has its maximum over the Irminger Sea (Fig. 12, top). Further regions of high storm track density are the Norwegian Sea and Barents Sea, the northern Mediterranean region, the Hudson Bay and the east coast of North America at around $50^{\circ} \mathrm{N}$. In general, the storm track density is highest at a southwest-northeast axis from the southeast coast of North America to the Norwegian Sea and higher over the oceans than over land. The differences in storm track density (Fig. 12, top) and its zonal mean (Fig. 14, 1st row, left) between FOCI-standard and FOCI-nest are small. The largest difference is an increased storm track density over the Irminger Sea in FOCI-nest 
compared to FOCI-standard which can be seen in the increased zonal mean storm track density at around $60-65^{\circ} \mathrm{N}$ as well. In the region of $40-80^{\circ} \mathrm{N}$ and $60-0^{\circ} \mathrm{W}$, the number of storm track points increases by $\sim 2 \%$ from 18.613 in FOCI-standard to 18.964 in FOCI-nest. Feature density patterns of ERA-15 given in Hoskins and Hodges (2002) and based on 6-hourly data are similar to track density in this thesis. In their study the maximum is located at southern Greenland and another local maximum is located south of Iceland compared to only one maximum in the Irminger Sea in this thesis.

Storm genesis is defined as the first track point and lysis as the last track point of each storm in the storm tracking output for this thesis.

Main storm genesis regions in FOCI-standard and FOCI-nest are the northern Mediterranean region, the Irminger Sea and the Arctic Ocean. Additionally, some storms form at around $40^{\circ} \mathrm{N}$ over the east coast of North America (Fig. 12, middle). Storm genesis density is higher in FOCI-nest than in FOCI-standard over the Irminger Sea and lower north of Finland and over the northern Mediterranean region. Local maxima of zonal mean genesis density (Fig. 14, 1st row, middle) are lower at around $43^{\circ} \mathrm{N}$ (northern Mediterranean region) and higher at $58-64^{\circ} \mathrm{N}$ (Irminger Sea) in FOCI-nest than in FOCI-standard. Compared to Hoskins and Hodges (2002), storm genesis regions are similarly located to both FOCI-standard and FOCI-nest in the Arctic Ocean. Their results differ in the location of a local storm genesis maximum east from the storm genesis region in the Irminger Sea in FOCI2 and in the dominance of the east coast of North America for storm genesis in their study.

Main storm lysis regions are over the Hudson Bay, the Labrador Sea and the Irminger Sea (Fig. 13, bottom). Storm lysis density is higher over the Irminger Sea in FOCInest than in FOCI-standard. So both the storm genesis and storm lysis are increased in FOCI-nest in this region. Additionally, storm lysis density is stronger in the Hudson Bay in FOCI-nest than in FOCI-standard. Zonal mean lysis density differences (Fig. 14, 1st row, right) are small. When comparing zonal mean lysis density in FOCI-standard and FOCI-nest, FOCI-nest has a slightly higher lysis density at $54^{\circ} \mathrm{N}$ and FOCI-standard has a higher lysis densities north of $74^{\circ} \mathrm{N}$. In both Hoskins and Hodges (2002) and FOCI2, storm lysis peaks in the Irminger Sea. The difference of this maximum to storm lysis density in the Hudson Bay and Labrador Sea is smaller in FOCI2 than in Hoskins and Hodges (2002). 
The sum of magnitude differences between the next and the current track point belonging to one common track divided by the number of track points in this area are used as a measure for mean growth and decay.

Storm growth and decay rate patterns show distinct regions of either storm growth or decay. Strong storm growth rates are found on the southeast coast of North America and the east coast of Greenland. Additionally, storms also tend to intensify east of these regions and over southern Europe.

Strong storm decay rates are found from the Baffin Bay to the Labrador Sea. Further regions of storm decay are the west coast of Europe and the North Atlantic at around $60^{\circ} \mathrm{N}$. The differences between both models are small but the storm decay rates over Baffin Bay are slightly weaker in FOCI-nest and the storm growth rates close to the southeast coast of North America are slightly stronger in FOCI-nest than in FOCI-standard (Fig. 13, top). Zonal mean of growth and decay rates in the North Atlantic region $\left(80^{\circ} \mathrm{W}-20^{\circ} \mathrm{E}\right.$, Fig. 14 2nd row, left) show overall storm growth south of $52^{\circ} \mathrm{N}$, storm decay at approximately $52-68^{\circ} \mathrm{N}$ and storm growth north of $68^{\circ} \mathrm{N}$. Both zonal mean storm growth and zonal mean storm decay are stronger in magnitude in FOCI-standard than in FOCI-nest. Compared to Hoskins and Hodges (2002), regions of mean decay in FOCI2 spread further south in the open North Atlantic. However, the general pattern of storm growth east of the North American coast and east of Greenland and storm decay at the west coast of Europe and west of Greenland are similar.

Mean storm intensity given as MSLP anomaly is strongest over the northwest coast of Scandinavia and over the North Atlantic between $50^{\circ} \mathrm{N}$ and $60^{\circ} \mathrm{N}$ (Fig. 13, middle). Storm intensity and its zonal mean over the North Atlantic region (Fig. 14, 2nd row, middle) behave very similarly in FOCI-standard and FOCI-nest. Only at around $68^{\circ} \mathrm{N}$, zonal mean storm intensity is higher in FOCI-nest than in FOCIstandard. The general magnitude pattern of storm intensity is similar to the one in Hoskins and Hodges (2002). FOCI2 differs from the results in their study with a storm intensity maximum at the west coast of Scandinavia that does not exist in their study.

Mean lifetime of analysed storms is highest at a southwest-northeast axis from the southeast coast of North America to the Norwegian Sea and generally higher over the oceans than over land (Fig. 13, bottom). When comparing zonal mean lifetime in FOCI-standard and FOCI-nest (Fig. 14, 2nd row, right), zonal mean lifetime is higher in FOCI-standard south of $32^{\circ} \mathrm{N}$ and higher in FOCI-nest north of $32^{\circ} \mathrm{N}$. The 
largest difference is found at around $75^{\circ} \mathrm{N}$, where zonal mean lifetime is more than half a day longer in FOCI-nest than in FOCI-standard. In contrast to zonal mean lifetime in Hoskins and Hodges (2002), zonal mean lifetime is longer than 5 days in FOCI-nest and in most regions of FOCI-standard, while mean lifetime in their study is lower than 5 days in large parts of the North Atlantic. It is to be noted that different tracking techniques might impact the resulting lifetime of storms. 


\section{Summary and Discussion}

In order to evaluate the validity of the results, limitations of the methods in this thesis should be considered. The short spin-up time of the model run leads to a warming trend in FOCI-nest (Fig. 1) even though sea-surface temperature (SST) should be constant in pre-industrial conditions. Therefore, all the results are based on a model that has not reached equilibrium. For a reliable analysis of FOCI-nest, the model should run longer until the equilibrium is reached but this is not feasible (yet) due to the vast computer resources it would require.

To determine whether differences between FOCI-standard and FOCI-nest are improvements or flaws, it would be ideal to compare the model data to pre-industrial observations. Since there is not enough data from this time-period or even the last decades, ERA-Interim reanalysis data (1979 to date) is used (except for precipitation). However, reanalysis data might include incorrect representations of reality due to the underlying model.

FOCI-standard does not have a Gulf Stream representation. This leads to the cold bias in the central North Atlantic in FOCI-standard (Fig. 2), which is a common problem in climate models with coarse ocean resolution (e.g. in Keeley et al., 2012). Increasing the horizontal ocean resolution leads to a representation of the Gulf Stream in FOCI-nest. The reduction of the SST biases in FOCI-nest compared to FOCI-standard is a first indication that the increased ocean resolution might result in an enhanced representation of overall climatology. All in all, this is confirmed for mean sea-level pressure (MSLP), zonal mean zonal wind $(u)$ and precipitation. The atmospheric response to the reduced SST biases leads to a reduction of the MSLP biases to the reanalysis (Fig. 3). Seasonal mean MSLP gradients are too similar in FOCI-standard (too weak in DJF, too strong in JJA) because the SST pattern includes the strong and constant cold SST bias in every season which leads to a weak seasonal cycle of MSLP in FOCI-standard compared to the reanalysis. Therefore a reduction of the cold SST bias in FOCI-nest improves the dominance of seasonal changes in SST and in MSLP which likely reduces the MSLP biases. Additionally, the biases in zonal mean $u$ are reduced (Fig. 4). However, the northward JJA polar jet stream bias is increased in FOCI-nest compared to FOCI-standard. This could be due to an increased MSLP gradient at around $60^{\circ} \mathrm{N}$. Mean precipitation of FOCI2 in comparison to GPCP data is enhanced with higher resolution as well, especially in the region of the North Atlantic Current at around 
$30^{\circ} \mathrm{W}$ (Fig. 5). In general however, precipitation in FOCI-nest is too high on west coasts and too low on east coasts in the North Atlantic region. In the region of the remaining cold bias $\left(45^{\circ} \mathrm{N}\right.$ and $\left.40^{\circ} \mathrm{W}\right)$ precipitation is too low. This interrelation of SST and precipitation biases was shown in Keeley et al. (2012) as well.

Bandpass-filtered precipitation is more concentrated over the Gulf Stream in FOCInest compared to FOCI-standard likely because it is connected to strong SST gradients (Fig. 7). In general, the bandpass-filtered and therefore synoptic scale precipitation variance might be slightly higher in FOCI-nest because of higher temperatures in FOCI-nest than in FOCI-standard.

The NAO index, calculated as the corresponding PC1 (Fig. 10) to the leading EOF (Fig. 9) of North Atlantic MSLP data, shows the typical multiyear variability for NAO in FOCI-standard but the variability in FOCI-nest has a much shorter periodicity and is much more regular. The regular 3-4 years period in FOCI-nest might be due to a strong ocean variability because the leading EOF of MSLP shows a high land-sea contrast. Such a distinct ocean variability might be caused by insufficient spin-up time in which case PC1 of FOCI-nest probably does not have the physical meaning of a NAO index even though its EOF shows the typical pattern of the NAO. Therefore, the results of the linear regression in FOCI-standard and FOCI-nest might not be comparable (Fig. 11). The reasons for this regular NAO variability in FOCI-nest are beyond the scope of this thesis. The linear regression of heat flux onto PC1 in FOCI-standard shows the expected increase of storm activity over eastern Europe, the northern Baltic Sea, the Irminger Sea and northern Greenland and a decrease south of $50^{\circ} \mathrm{N}$ in positive NAO phases.

MSLP variance (Fig. 6) and heat flux $\left(\overline{v^{\prime} T^{\prime}}\right.$, Fig. 8) differences between FOCInest and FOCI-standard show similar patterns, which indicates that both metrics are equally suitable to identify storm activity. Both show strongest storm activity over the southeast coast of North America at around $50^{\circ} \mathrm{N}$ in DJF. Heat flux and MSLP variance in FOCI-nest are generally higher north of $55^{\circ} \mathrm{N}$ and lower south of $55^{\circ} \mathrm{N}$ compared to FOCI-standard which reduces the MSLP variance biases to the reanalysis. Only the MSLP variance bias in the region between the west coast of Ireland and the east coast of Greenland is higher in FOCI-nest than in FOCIstandard in DJF. This could be due to the missing southwest-northeast tilt of the modelled North Atlantic Drift. Even though the absolute values of MSLP variance are higher in SON than in MAM, the biases of MSLP variance are smaller in SON. 
This might lead to better storm modelling of FOCI2 in SON than in MAM even though the biases of absolute MSLP values are higher in SON than in MAM. The heat flux is increased at the coast of Greenland and over the Labrador Sea likely because the warm and salty Irminger Current can be resolved in FOCI-nest, while it is missing in FOCI-standard. However the warm SST bias in the Labrador Sea could be due to the short spin-up time. Danek et al. (2019) showed with their model FESOM with locally eddy-resolving ocean resolution that SST biases, mixed layer depth and sea ice extend largely depend on spin-up time in high $(5-15 \mathrm{~km})$ resolution models. Spin-up of the ocean generally takes longer than spin-up of the atmosphere.

Storm density does not fully align with MSLP variance and heat flux. The storm track density maximum (Fig. 12) is not located over the southeast coast of North America at around $50^{\circ} \mathrm{N}$ but over the Irminger Sea, where MSLP variance and heat flux are still high but do not display a local maximum. The reason for this difference may lie in a high number of short reaching $\left(<10^{3} \mathrm{~km}\right)$ storms over the southeast coast of North America that cause the heat flux and MSLP variance but are filtered out by the tracking algorithm. Additionally, the tracking algorithm uses a T63 grid $\left(\sim 2^{\circ}\right.$ resolution $)$ to remove small scale anomalies, whereas the Eulerian approaches use 2-8 days bandpass-filtering to remove short anomalies which might cause some deviations in the results.

The differences in storm identification methods need to be considered when comparing results with literature. In this thesis 2-8 days bandpass-filtering was chosen for the synoptic time scale filtering, whereas Keeley et al. (2012) used 2-6 days bandpass-filtering.

The differences between storm tracking algorithms were analysed in the IMILAST project by Neu et al. (2013). They concluded, based on 15 storm tracking algorithms, that the results of storm tracking do not generally depend on algorithm feature choices (e.g. vorticity vs. MSLP) or on temporal resolution. Even though they did not examine the storm tracking algorithm used in this thesis (Hodges, 1995, 1999; Hoskins and Hodges, 2002), the differences in storm-tracking results between 12-hourly FOCI2 data and 6-hourly ERA-15 data (Hoskins and Hodges, 2002) are probably partly based on data differences and not only on temporal resolution and method. However, Hoskins and Hodges (2002) mentioned that storm tracking based on MSLP anomalies can be biased by the Icelandic low.

While track density in both FOCI-standard and FOCI-nest peaks in the Irminger 
Sea (Fig. 12), it peaks west and east of it in the analysis of storms by Hoskins and Hodges (2002). This might be due to a missing representation of the Irminger Current in FOCI-standard and a weak representation in FOCI-nest or problems due to the Greenland topography in FOCI2, but further research is needed. More storm genesis over the North American coast in Hoskins and Hodges (2002) seems to contradict the positive bias of MSLP variance in FOCI-standard and FOCI-nest compared to ERA-Interim in this region. Additionally, this positive bias in MSLP variance seems to contradict the larger regions of storm growth in FOCI2 (Fig. 13) than in the study of Hoskins and Hodges (2002). To resolve the seemingly contradictions to their study, it would be interesting to analyse 12-hourly ERA reanalysis data with the same storm tracking method as FOCI-standard and FOCI-nest and compare the results. In a comparison of the storm tracking results of FOCI-standard, FOCI-nest shows a slightly higher overall storm track density (Fig. 12). In the zonal means of storm tracking results in FOCI-standard and FOCI-nest (Fig. 14), the largest differences are locally higher track and genesis densities at around $60^{\circ} \mathrm{N}$ in FOCI-nest, higher magnitudes of mean storm growth and decay in FOCI-standard and a longer lifetime of storms north of $32^{\circ} \mathrm{N}$ in FOCI-nest. The causes for the increased storm activity and different behaviour of storms, especially the higher lifetime in FOCI-nest than in FOCI-standard need further research. One hypothesis would be that the increased lifetime in FOCI-nest compared to FOCI-standard is due to the higher sea-surface temperature in FOCI-nest.

Wilson et al. (2009) pointed out that even though North Atlantic storm tracks would form as a result of atmosphere dynamics alone, added ocean dynamics and orography lead to a sharper North Atlantic storm track that is shifted further north. In Small et al. (2014) sharper ocean fronts led to an overall increase in storm track activity. These results can be partially confirmed by this analysis. Seasonal variance of MSLP and meridional heat flux shift northward in FOCI-nest. However the increase in storm track activity is small. This could be due to the eddy parameterization in FOCI-standard that already accounts for a similar amount of oceanic heat transport. Additionally, Small et al. (2014) used a higher resolution atmospheric model $\left(1 / 2^{\circ}\right)$ than the one in OpenIFS $\left(1.125^{\circ}\right)$, so this might explain the missing increase in storm activity in FOCI-nest compared to FOCI-standard.

The air-sea interactions in FOCI2 are calculated by the atmosphere model, OpenIFS, which has coarser resolution $\left(1.125^{\circ}\right)$ compared to the ocean resolution $\left(1 / 2^{\circ}\right.$, in FOCI_VIKING10: $1 / 10^{\circ}$ ). Therefore, the air-sea fluxes do not allow for sharp SST 
gradients and small scale anomalies. In future studies it would be interesting to analyse the impact of a higher resolution atmosphere in addition to an eddy-resolving ocean on storm modelling.

\section{Conclusion}

Increasing the ocean resolution from $1 / 2^{\circ}$ to $1 / 10^{\circ}$ in the North Atlantic in FOCI2OpenIFS led to an overall reduction of model biases. Biases in mean MSLP and $u$ as well as MSLP variance strongly depend on the season. Heat flux $\left(\overline{v^{\prime} T^{\prime}}\right)$ and MSLP variance both indicate strongest storm activity in DJF over the southeast coast of North America at around $50^{\circ} \mathrm{N}$ and a northward shift of the storm activity in FOCI-nest compared to FOCI-standard. Additionally, zonal mean $u$ indicates a northward shift of the polar jet stream in FOCI-nest compared to FOCI-standard. The EOF analysis of North Atlantic MSLP shows an irregular multiyear variability in FOCI-standard but a regular 3-4 years variability in FOCI-nest. Thus, the leading EOF of MSLP in FOCI-nest does not resemble NAO in periodicity, but only in spatial pattern. Additionally, the leading EOF pattern is less dominant in FOCIstandard than in the reanalysis at around $40^{\circ} \mathrm{N}$. Spatial distribution of storm track density, storm genesis and lysis, storm growth, mean intensity and mean lifetime is similar for FOCI-standard and FOCI-nest. The largest differences are locally higher track and genesis densities at around $60^{\circ} \mathrm{N}$, lower magnitudes of zonal mean storm growth and decay and a higher lifetime of storms north of $32^{\circ} \mathrm{N}$ in FOCI-nest than in FOCI-standard. It would be interesting to study the reasons for this increased lifetime in further research, for example by examining the heat and momentum fluxes along storm tracks. In addition, the impact of an eddy-resolving ocean might be limited by the atmospheric resolution in this study $\left(1.125^{\circ}\right)$, so it would be interesting to repeat the analysis with data from a FOCI2-OpenIFS model run with a higher atmospheric resolution. 


\section{Acknowledgements}

Thanks to Dr. K. Hodges for providing me with his storm tracking algorithm (Hodges, 1995, 1999; Hoskins and Hodges, 2002).

All plots were created with matplotlib (Hunter, 2007) and numpy (Harris et al., 2020). Maps are based on cartopy (Met Office, 2010 - 2015) in an EquidistantConic projection. 


\section{$7 \quad$ References}

\section{References}

Barnes, E. A., and L. M. Polvani (2015), CMIP5 Projections of Arctic Amplification, of the North American/North Atlantic Circulation, and of Their Relationship, Journal of Climate, 28(13), 5254-5271, doi:10.1175/JCLI-D-14-00589.1.

Blackmon, M. L., J. M. Wallace, N.-C. Lau, and S. L. Mullen (1977), An Observational Study of the Northern Hemisphere Wintertime Circulation, Journal of the Atmospheric Sciences, 34(7), 1040-1053, doi:10.1175/1520-0469(1977)034〈1040: AOSOTN $>2.0 . \mathrm{CO} ; 2$.

Booth, J. F., S. Wang, and L. Polvani (2013), Midlatitude storms in a moister world: lessons from idealized baroclinic life cycle experiments, Climate dynamics, 41(3-4), 787-802, doi:10.1007/s00382-012-1472-3.

Brayshaw, D. J., B. Hoskins, and M. Blackburn (2009), The Basic Ingredients of the North Atlantic Storm Track. Part I: Land-Sea Contrast and Orography, Journal of the Atmospheric Sciences, 66(9), 2539-2558, doi:10.1175/2009JAS3078.1.

Brayshaw, D. J., B. Hoskins, and M. Blackburn (2011), The Basic Ingredients of the North Atlantic Storm Track. Part II: Sea Surface Temperatures, Journal of the Atmospheric Sciences, 68(8), 1784-1805, doi:10.1175/2011JAS3674.1.

Chang, E. K. (2009), Are band-pass variance statistics useful measures of storm track activity? Re-examining storm track variability associated with the NAO using multiple storm track measures, Climate dynamics, 33(2-3), 277-296, doi: 10.1007/s00382-009-0532-9.

Craig, A., S. Valcke, and L. Coquart (2017), Development and performance of a new version of the OASIS coupler, OASIS3-MCT_3. 0., Geoscientific Model Development, 10(9), doi:10.5194/gmd-10-3297-2017.

Danek, C., P. Scholz, and G. Lohmann (2019), Effects of High Resolution and Spinup Time on Modeled North Atlantic Circulation, Journal of Physical Oceanography, 49(5), 1159-1181, doi:10.1175/JPO-D-18-0141.1.

Dawson, A. (2016), eofs: A Library for EOF Analysis of Meteorological, Oceanographic, and Climate Data, Journal of Open Research Software, 4(1)(e14), doi: http://doi.org/10.5334/jors.122. 
Debreu, L., C. Vouland, and E. Blayo (2008), AGRIF: Adaptive grid refinement in Fortran, Computers \& Geosciences, 34(1), 8-13, doi:10.1016/j.cageo.2007.01.009.

Dee, D. P., et al. (2011), The ERA-Interim reanalysis: Configuration and performance of the data assimilation system, Quarterly Journal of the royal meteorological society, 137(656), 553-597, doi:10.1002/qj.828.

ECMWF (2014), IFS DOCUMENTATION CY40r1, available at: https://www.ecmwf.int/en/publications/ifs-documentation, CY40r1.

Emanuel, K. A., M. Fantini, and A. J. Thorpe (1987), Baroclinic Instability in an Environment of Small Stability to Slantwise Moist Convection. Part I: TwoDimensional Models, Journal of the Atmospheric Sciences, 44(12), 1559-1573, doi:10.1175/1520-0469(1987)044〈1559:BIIAEO〉2.0.CO;2.

Fichefet, T., and M. A. M. Maqueda (1997), Sensitivity of a global sea ice model to the treatment of ice thermodynamics and dynamics, Journal of Geophysical Research: Oceans, 102(C6), 12,609-12,646, doi:10.1029/97JC00480.

Francis, J. A., and S. J. Vavrus (2012), Evidence linking Arctic amplification to extreme weather in mid-latitudes, Geophysical research letters, 39(6), doi: 10.1029/2012GL051000.

Gent, P. R., and J. C. McWilliams (1990), Isopycnal mixing in ocean circulation models, Journal of Physical Oceanography, 20(1), 150-155, doi:10.1175/ 1520-0485(1990)020〈0150:IMIOCM $>2.0 . \mathrm{CO} ; 2$.

Greatbatch, R., X. Zhai, M. Claus, L. Czeschel, and W. Rath (2010), Transport driven by eddy momentum fluxes in the Gulf Stream Extension region, Geophysical Research Letters, 37(24), doi:10.1029/2010GL045473.

Haarsma, R., et al. (2020), HighResMIP versions of EC-Earth: EC-Earth3P and EC-Earth3P-HR-description, model computational performance and basic validation, Geoscientific Model Development, 13(8), 3507-3527, doi:10.5194/ gmd-13-3507-2020.

Hallberg, R. (2013), Using a resolution function to regulate parameterizations of oceanic mesoscale eddy effects, Ocean Modelling, 72, 92 - 103, doi:10.1016/j. ocemod.2013.08.007.

Harris, C. R., et al. (2020), Array programming with NumPy, Nature, 585(7825), 357-362, doi:10.1038/s41586-020-2649-2. 
Held, I. M., and B. J. Soden (2006), Robust Responses of the Hydrological Cycle to Global Warming, Journal of Climate, 19(21), 5686-5699, doi:10.1175/JCLI3990. 1.

Hodges, K. I. (1995), Feature Tracking on the Unit Sphere, Monthly Weather Review, 123(12), 3458-3465, doi:10.1175/1520-0493(1995)123〈3458:FTOTUS〉2.0.CO;2.

Hodges, K. I. (1999), Adaptive Constraints for Feature Tracking, Monthly Weather Review, 127(6), 1362-1373, doi:10.1175/1520-0493(1999)127〈1362:ACFFT $〉 2.0$. $\mathrm{CO} ; 2$.

Hoskins, B., and K. Hodges (2019a), The annual cycle of Northern Hemisphere storm tracks. Part I: Seasons, Journal of Climate, 32(6), 1743-1760, doi:10.1175/ JCLI-D-17-0870.1.

Hoskins, B., and K. Hodges (2019b), The annual cycle of Northern Hemisphere storm tracks. Part II: Regional detail, Journal of Climate, 32(6), 1761-1775, doi: 10.1175/JCLI-D-17-0871.1.

Hoskins, B. J., and K. I. Hodges (2002), New perspectives on the Northern Hemisphere winter storm tracks, Journal of the Atmospheric Sciences, 59(6), 10411061, doi:10.1175/1520-0469(2002)059〈1041:NPOTNH $\rangle$ 2.0.CO;2.

Hoskins, B. J., and P. J. Valdes (1989), On the Existence of Storm-Tracks, Journal of the Atmospheric Sciences, 47(15), 1854-1864, doi:10.1175/1520-0469(1990) 047〈1854:OTEOST $>2.0 . \mathrm{CO} ; 2$.

Huffman, G. J., R. F. Adler, D. T. Bolvin, and G. Gu (2009), Improving the global precipitation record: GPCP version 2.1, Geophysical Research Letters, 36(17), doi:10.1029/2009GL040000.

Hunter, J. D. (2007), Matplotlib: A 2D graphics environment, Computing in Science \& Engineering, 9(3), 90-95, doi:10.1109/MCSE.2007.55.

Hurrell, J. (last modified: 14th Aug. 2020), The Climate Data Guide: Hurrell North Atlantic Oscillation (NAO) Index (station-based), National Center For Atmospheric Research Staff (Eds), Available at: https://climatedataguide.ucar.edu/climate-data/hurrell-north-atlanticoscillation-nao-index-pc-based.

Keeley, S., R. Sutton, and L. Shaffrey (2012), The impact of North Atlantic sea surface temperature errors on the simulation of North Atlantic European region 
climate, Quarterly Journal of the Royal Meteorological Society, 138(668), 17741783, doi:10.1002/qj.1912.

Kjellsson, J., J. Streffing, G. Carver, and M. Koehler (2020), From weather forecasting to climate modelling using OpenIFS, pp. 38-41, doi:10.21957/469hc10jk5.

Madec, G. (2016), NEMO ocean engine, version 3.6 stable, Note du Pole de modelisation de l'Institut Pierre-Simon Laplace, available at: https://www.nemoocean.eu/doc/.

Madec, G., and M. Imbard (1996), A global ocean mesh to overcome the North Pole singularity, Climate Dynamics, 12(6), 381-388, doi:10.1007/BF00211684.

Matthes, K., et al. (2020), The Flexible Ocean and Climate Infrastructure Version 1 (FOCI1): Mean State and Variability, Geoscientific Model Development Discussions, doi:10.5194/gmd-13-2533-2020.

Met Office (2010 - 2015), Cartopy: a cartographic python library with a matplotlib interface, http://scitools.org.uk/cartopy.

Neu, U., et al. (2013), IMILAST: A Community Effort to Intercompare Extratropical Cyclone Detection and Tracking Algorithms, Bulletin of the American Meteorological Society, 94(4), 529-547, doi:10.1175/BAMS-D-11-00154.1.

Raphael, M. N. (1997), The relationship between the transient, meridional eddy sensible and latent heat flux, Journal of Geophysical Research: Atmospheres, 102(D12), 13,487-13,494, doi:10.1029/97JD00811.

Roberts, M. J., et al. (2019), Description of the resolution hierarchy of the global coupled HadGEM3-GC3.1 model as used in CMIP6 HighResMIP experiments, Geoscientific Model Development, 12(12), 4999-5028, doi:10.5194/gmd-12-4999-2019.

Schulzweida, U. (2019), CDO User Guide, doi:10.5281/zenodo.3539275.

Small, R. J., R. A. Tomas, and F. O. Bryan (2014), Storm track response to ocean fronts in a global high-resolution climate model, Climate dynamics, 43(3-4), 805828, doi:10.1007/s00382-013-1980-9.

Wang, C., L. Zhang, S.-K. Lee, L. Wu, and C. R. Mechoso (2014), A global perspective on CMIP5 climate model biases, Nature Climate Change, 4(3), 201-205, doi:10.1038/nclimate2118. 
Wang, J., H.-M. Kim, and E. K. M. Chang (2017), Changes in Northern Hemisphere Winter Storm Tracks under the Background of Arctic Amplification, Journal of Climate, 30(10), 3705-3724, doi:10.1175/JCLI-D-16-0650.1.

Willison, J., W. A. Robinson, and G. M. Lackmann (2015), North Atlantic Storm-Track Sensitivity to Warming Increases with Model Resolution, Journal of Climate, 28(11), 4513-4524, doi:10.1175/JCLI-D-14-00715.1.

Wilson, C., B. Sinha, and R. G. Williams (2009), The Effect of Ocean Dynamics and Orography on Atmospheric Storm Tracks, Journal of Climate, 22(13), 3689-3702, doi:10.1175/2009JCLI2651.1. 


\section{Erklärung}

Hiermit erkläre ich, dass ich die vorliegende Arbeit selbstständig und ohne fremde Hilfe angefertigt und keine anderen als die angegebenen Quellen und Hilfsmittel verwendet habe.

Die eingereichte schriftliche Fassung der Arbeit entspricht der auf dem elektronischen Speichermedium.

Weiterhin versichere ich, dass diese Arbeit noch nicht als Abschlussarbeit an anderer Stelle vorgelegen hat.

Ort, Datum

Johanna Knauf 